\title{
Influence of Cold Spray Parameters on Bonding Mechanisms: A Review
}

\author{
Surinder Singh ${ }^{1}\left(\mathbb{D}\right.$, R. K. Singh Raman ${ }^{2,3}{ }^{\circledR}$, Christopher C. Berndt ${ }^{1, *}$ and Harpreet Singh ${ }^{4, *}$ \\ 1 Department of Mechanical Engineering and Product Design Engineering, Faculty of Science, Engineering and \\ Technology, "Surface Engineering for Advanced Materials"—SEAM, Swinburne University of Technology, \\ H38, P.O. Box 218, Hawthorn, VIC 3122, Australia; surindersingh@swin.edu.au \\ 2 Department of Mechanical and Aerospace Engineering, Monash University, Clayton, VIC 3800, Australia; \\ raman.singh@monash.edu \\ 3 Department of Chemical Engineering, Monash University, Clayton, VIC 3800, Australia \\ 4 Department of Mechanical Engineering, Indian Institute of Technology Ropar, Rupnagar 140001, India \\ * Correspondence: cberndt@swin.edu.au (C.C.B.); harpreetsingh@iitrpr.ac.in (H.S.)
}

Citation: Singh, S.; Raman, R.K.S.; Berndt, C.C.; Singh, H. Influence of Cold Spray Parameters on Bonding Mechanisms: A Review. Metals 2021, 11, 2016. https://doi.org/10.3390/ met11122016

Academic Editors: Alberto

Moreira Jorge, Jr. and

Akio NISHIMOTO

Received: 3 November 2021

Accepted: 9 December 2021

Published: 13 December 2021

Publisher's Note: MDPI stays neutral with regard to jurisdictional claims in published maps and institutional affiliations.

\begin{abstract}
The cold spray process is governed by the impact of high velocity feedstock particles onto a substrate without melting. Hence, the bulk material properties are retained. However, it is challenging to achieve good adhesion strength. The adhesion strength depends on factors such as the cold spray process parameters, substrate conditions, coating/substrate interactions at the interface and feedstock material properties. This review examines fundamental studies concerning the adhesion mechanisms of cold spray technology and considers the effect of cold spray input parameters such as temperature, stand-off-distance, pressure, process gas, spray angle, and traverse speed of the cold spray torch on the bonding mechanism and adhesion strength. Furthermore, the effects of substrate conditions such as temperature, hardness, roughness and material on the adhesion mechanism are highlighted. The effect of feedstock properties, such as feed rate, shape and size are summarized. Understanding the effect of these parameters is necessary to obtain the optimal input parameters that enable the best interfacial properties for a range of coating/substrate material combinations. It is expected that feedstock of spherical morphology and small particle size $(<15 \mu \mathrm{m})$ provides optimal interfacial properties when deposited onto a mirror-finished substrate surface using high pressure cold spray. Deep insights into each parameter exposes the uncovered potential of cold spray as an additive manufacturing method.
\end{abstract}

Keywords: surface engineering; coating; cold spray; bonding mechanism; adhesion strength; spray parameter; impact behavior

\section{Introduction}

Surface modification by applying coatings is used in manufacturing industries to enhance surface properties. Surface coatings protect the base material and save cost with respect to component replacement, material degradation and service life of the coated components [1-4]. There are several coating techniques such as active screen plasma treatment, physical vapor deposition (PVD), thermal spray and laser deposition techniques that are used according to specific requirements such as coating thickness, type of bonding, bonding strength, material to be coated, temperature of the coating process and desired properties of the coating [3-7]. Methods based on atomic and vapor deposition such as active screen plasma nitriding, chemical vapor deposition, PVD, and conventional plasma nitriding are recommended for thin films; while methods based on particle deposition such as laser cladding, high velocity oxygen fuel spray, wire-arc spray, and cold spray (CS) are recommended for thick coatings [8,9]. Recent (2021) and most prominent techniques for the development of thin films and thick coatings, which work on lower deposition temperatures as compared to their conventional counterparts, are active plasma screen treatment and CS. 
The CS process was developed in the mid-1980s by the Siberian division of the Russian Academy at the Institute of Theoretical and Applied Mechanics, whereas it emerged in North America in the 1990s [10,11]. In the early 1990s, Russian scientists from the Obninsk Center for Powder Spraying (OCPS) innovated CS equipment that was more economic [11], which enabled the onsite repair of defective components. Introduction of this equipment made Russia the lead manufacturers of CS systems. The development and use of CS systems outside Russia were initiated in the early 2000s. Subsequently, there was an increasing interest in CS technology that resulted in an exponential growth in publications and citations (Figure 1).

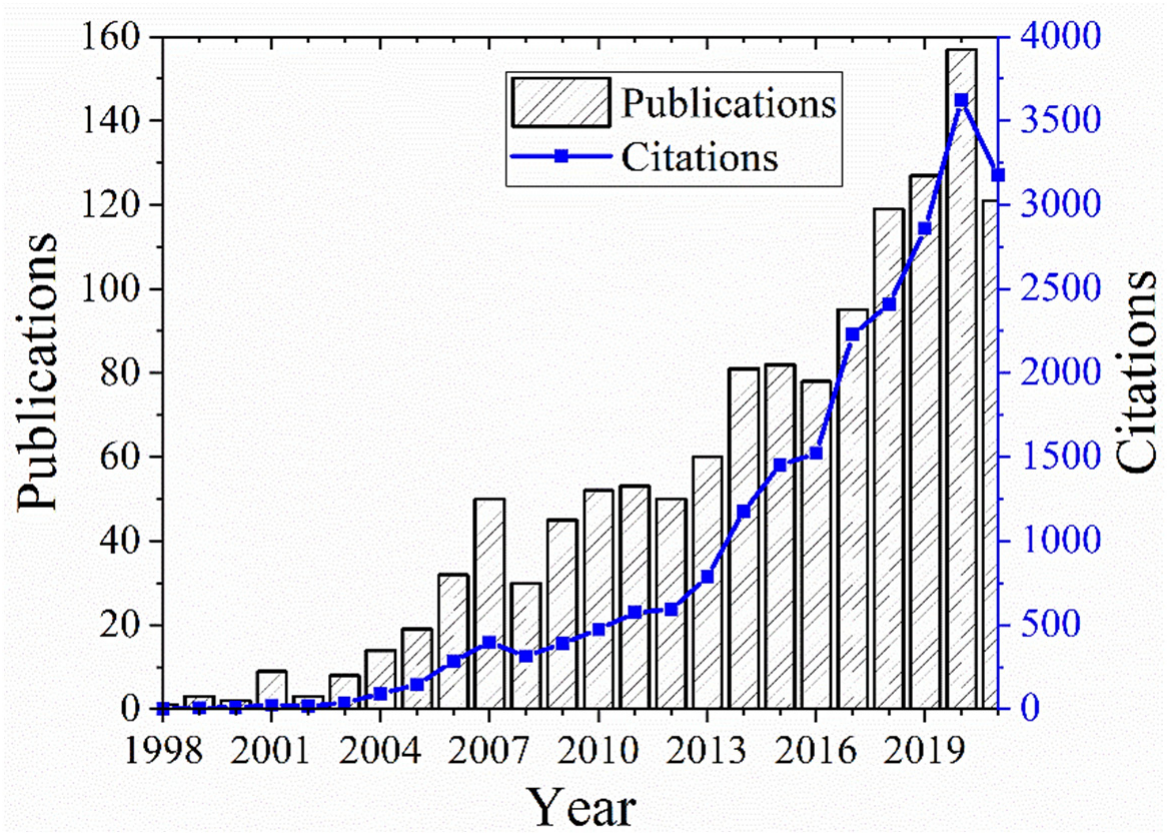

Figure 1. Number of publications on cold spray technology and their citations per year (until August 2021; Scopus database).

The CS process uses a high pressure supersonic gas jet to accelerate fine powder particles at or above a critical velocity $(500-1200 \mathrm{~m} / \mathrm{s})$ for their deposition as a coating. The kinetic energy released during the impact of the particle upon the substrate ruptures any surface oxides and plastically deforms the particle as it approaches the clean surface of the substrate; hence promoting bonding of a coating [12-14].

The formation of a CS coating consists of two steps; (i) initial particle-substrate contact that is followed by (ii) particle-particle interactions. In the first step, bonding/adhesion at the interface of the substrate and first layer of the particles is attained, followed by the formation of consecutive layers by particle-particle interactions [15-18]. These layer-bylayer formations result in thick coatings $[19,20]$.

Successful deposition of cold sprayed particles is accomplished when they strike the substrate at a velocity greater than the critical velocity for a given feedstock material. The critical velocity depends on the properties of the material and its morphology [21-24]. Moreover, the characteristics of the oxide layer on the particle surface also determines its critical velocity [18]. Yu et al. [25] found that greater oxide layer thicknesses, requires a higher critical velocity to achieve effective bonding at the interface. Particle impact, oxidelayer breakdown, particle deformation, bond formation or interlocking at the interface, localization of strain and densification of the coating layers are the parameter responsible for an effective CS deposition [15,17,26-29].

CS has been used to produce protective coatings and performance enhancing surface modifications, ultra-thick coatings, free forms and near net shapes. CS is a relatively young technology and further R\&D is still needed to understand and control the process; as well as, to develop engineered coatings with desired properties for specific applications. Gov- 
ernment laboratories, academic institutions, and industries have undertaken considerable R\&D efforts [30-32].

CS technology has demonstrated potential for the deposition of thick metallic/nonmetallic coatings with enhanced properties when compared to methods such as thermal spray and laser cladding $[7,33]$. CS offers oxide-free coatings because processing can be accomplished in the solid state [28,34-36]. Further, CS provides dense coatings with porosities as low as $<1 \%$ achievable $[2,36,37]$. It has been reported that material properties of cold sprayed materials are comparable with those of their counterpart bulk materials.

CS of soft and ductile materials on a soft substrate (i.e., a soft-on-soft interface) is most successful compared to hard-on-hard, soft-on-hard, and hard-on-soft interfaces [38-41]. Coating of brittle materials on hard-interfaces (a hard-on-hard interface), the effect of residual stresses on the coating properties, and delamination of thick coatings remain technical challenges [33,42-44]. However, a wide range of materials such as copper, titanium, steel, and high entropy alloys can be cold sprayed by optimizing the spray parameters, substrate conditions and feedstock conditions [5,36,45-49].

An optimized set of spray parameters can be obtained if the effect of each parameter on high energy impact is understood $[19,50]$. Therefore, an extensive review of each spray parameter, feedstock properties, and substrate conditions is presented. The present review provides a single platform to understand the bonding mechanism of CS in relation to its input conditions.

\section{Adhesion Mechanism in Cold Spray}

CS is a solid-state deposition process since the feedstock is not melted; however, the kinetic energy of the high velocity particles leads to interfacial deformation as well as localized heat at the location of impact [17,51,52]. The conversion of kinetic energy into deformation and heat results in mechanical interlocking as well as metallurgical bonding at the interface [53]. The bonding at the interface in CS is still mysterious to some degree since there is no exact theory that explains the bonding mechanism at the interface. However, the literature mentions that the spray particles require a certain amount of energy in combination with a critical velocity at an optimum temperature, for effective bonding to occur [12-14,32]. High strain rate deformation is observed around the particle-substrate interface, which produces a microscopic protrusion of material with localized heating. The combination of material deformation at the atomic level and localized heat may lead to metallurgical bonding [54,55].

Bonding at the interface is governed by the severe plastic deformation of the materials; which, with associated adiabatic shear instability (ASI) at the interface, leads to the metal-jet formation $[12,17,39,56]$. The high velocity particle impacts cause breakage of the native oxide layer at the surfaces, providing a particle-to-substrate contact. This true contact of the particles with the substrate may lead to the jet formation that is governed by ASI $[16,20,28]$. However, Hassani-Gangaraj et al. [57] contradicted the work of Assadi et al. [13] and Grujicic et al. [15] by reporting that ASI is not necessary for bonding in CS. Responding to the comments of Assadi et al. [58], Hassani-Gangaraj et al. [59] defended their simulationbased research that supported ASI was not required for bonding. These, and other scientific contradictions highlight that adhesion mechanism(s) of CS coatings is an unresolved topic that requires further investigation.

Delamination and poor adhesion strength of soft-on-hard and hard-on-hard interfaces are of great concern for industries such as the marine, nuclear, aerospace, automotive and electronics. Thus, understanding the mechanism of bonding can address the issue of poor adhesion and delamination, which would assist the advanced manufacturing sector. For instance, thick copper coatings on steel (SS316L) plates that would exhibit properties comparable to that of bulk $\mathrm{Cu}$, along with good adhesion, are in high demand for the vacuum vessel of Tokamaks [9,55,60-62]. In this regard, Singh et al. [63] investigated the bonding mechanism of $\mathrm{Cu}$ particles on steel substrates (soft-on-hard interface) by altering the CS parameters and the substrate conditions. 
Drehmann et al. [19], Wustefled et al. [41] and Dietrich et al. [49] investigated the bonding mechanism for cold sprayed $\mathrm{Al}$ on an $\mathrm{Al}_{2} \mathrm{O}_{3}$ substrate (soft-on-hard). Their results revealed that bonding of $\mathrm{Al}$ particles on super-finished monocrystalline sapphire substrate occurred due to deformation-induced recrystallization in the vicinity of the particle-substrate interface, as represented in Figure 2. The formation of nano-sized grains at the vicinity of the interface assists metallurgical bonding, which results in improved adhesion strength between ductile $\mathrm{Al}$ particles and the $\mathrm{Al}_{2} \mathrm{O}_{3}$ monocrystalline ceramic substrate. Therefore, there are many factors that influence the adhesion strength, and these need optimization to achieve the best adhesion strength of the CS coating.

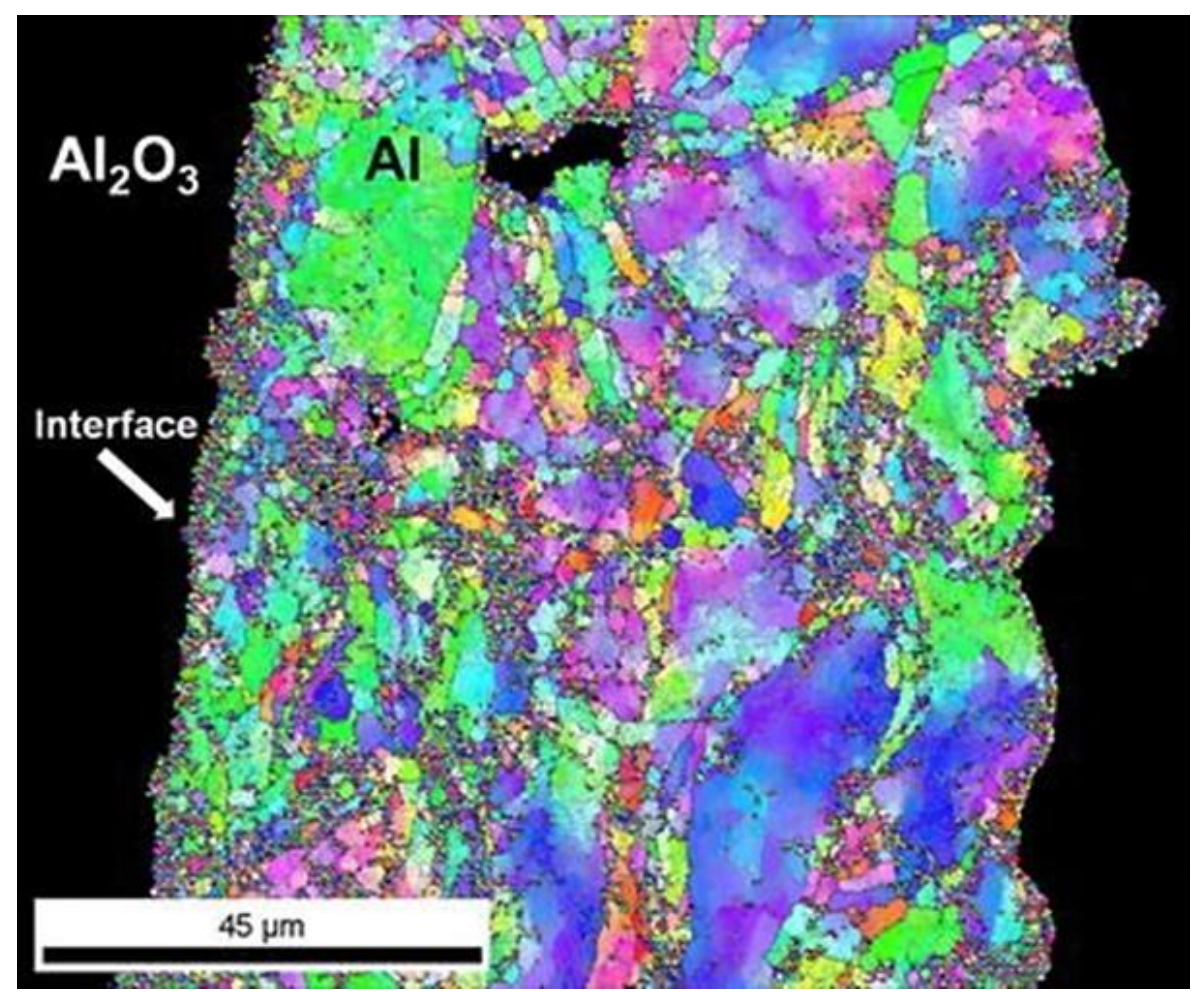

Figure 2. Electron Backscatter Diffraction (EBSD) image of cold sprayed $\mathrm{Al}$ coating on $\mathrm{Al}_{2} \mathrm{O}_{3}$ substrate showing recrystallization at the vicinity of the particle substrate interface. \{Reprinted by permission from, Springer Nature, Journal of Thermal Spray Technology, [19]\}.

Pre-treatments are used: for example, modifying the substrate surface roughness by grit blasting, pre-heating the substrate to circumvent the residual stress evolution, and adjusting the substrate hardness by thermal treatment [64-66]. CS input parameters such as particle velocity, gas temperature, nozzle geometry, stand-off-distance, particle size and morphology, and type of the process gas play significant roles in the quality of the final coating and the bonding mechanism at the interface [46,67-69].

Additionally, the type and model of the CS system influence the bonding mechanism [70]. There are several parameters (highlighted in Figure 3) that influence the bonding mechanism and these need to be adjusted for specific particle-substrate combinations. 


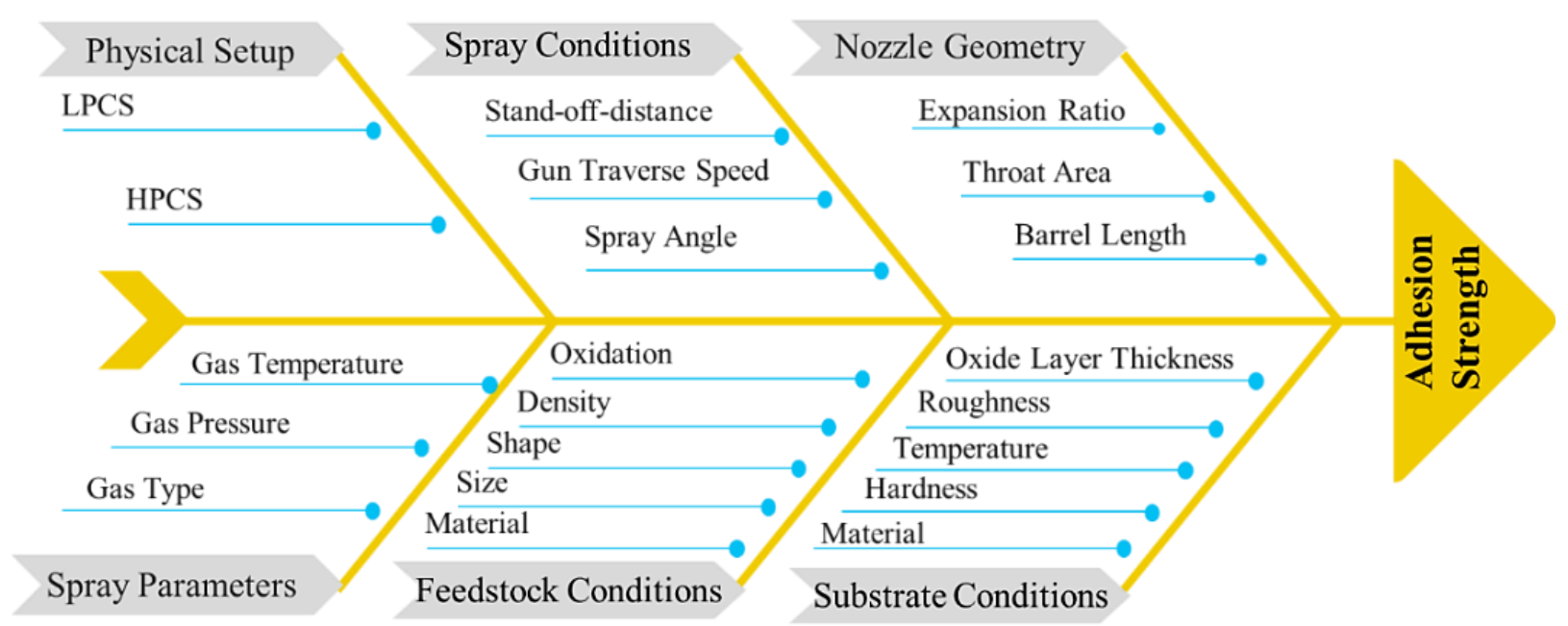

Figure 3. Fishbone diagram representing parameters that influence the adhesion strength in CS. Note: LPCS = low pressure cold spray, HPCS = high pressure cold spray.

\section{Effect of Cold Spray Setup}

Currently, there are two prime arrangements for CS: low pressure cold spray (LPCS), and high pressure cold spray (HPCS). The working principles of LPCS and HPCS systems are shown in Figure 5. The input parameters representing the working capacities of these systems are reported in Table 1. The impact velocity of particles in the LPCS process is lower than that in the HPCS particles [44,51,71], resulting in large differences in their kinetic energies. The particle velocity is controlled by their size, shape and intrinsic material.

Microstructural analysis reveals differences between these CS processes. In the HPCS process, the high particle velocity leads to the formation of adiabatic shear bands. The formation of these bands results in bonding and adhesion at the interface [72,73]. Papyrin et al. [74] deposited $\mathrm{Cu}$ on steel with HPCS, and $\mathrm{Al}$ and $\mathrm{Cu}$ on $\mathrm{Al}$ substrates with LPCS (Figure 4). Parachute-shaped splats were observed for HPCS, which were attributed to the high strain rates experienced by the $\mathrm{Cu}$ particles upon impact with the substrate [75]. This CS coating exhibited a high density with porosity less than $1 \%$. On the other hand, for LPCS Cu coatings, the lower particle velocities resulted in comparatively uniformly deformed and flattened splats without jet formation (Figure 4). The authors also observed the presence of dark splat boundaries for LPCS and light splat boundaries for HPCS after etching. Thus, the LPCS coatings underwent a higher degree of etching than the HPCS coatings. This difference in appearance of the splat boundary depicts a weak inter-particle cohesion for LPCS and implies a lower deposition efficiency for LPCS in comparison with HPCS. The lower deposition efficiency in LPCS is attributed to absence of an ASI contribution to the bonding mechanism $[10,50]$.

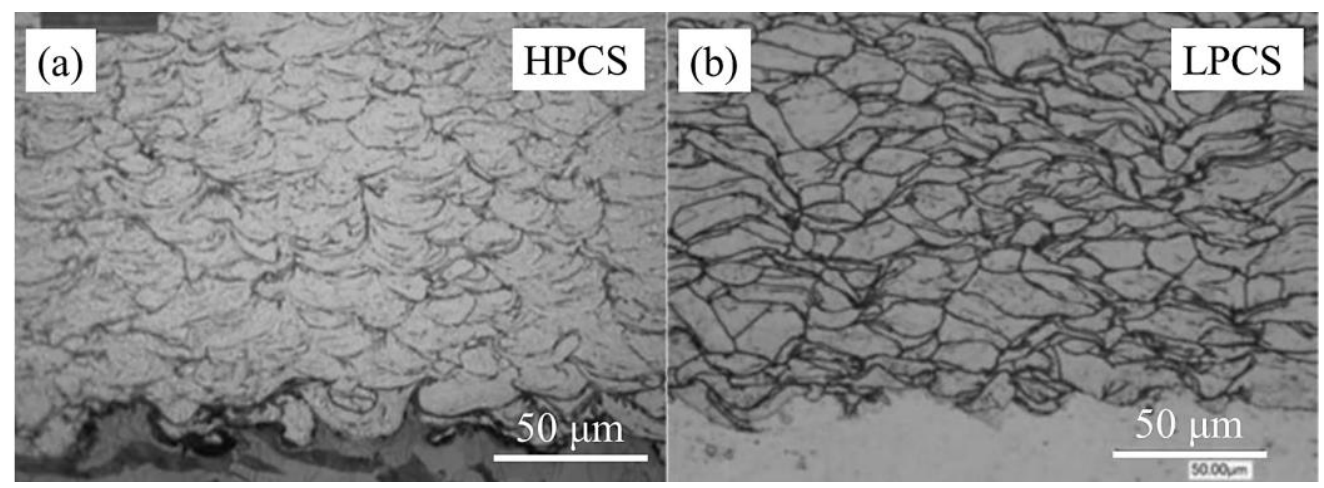

Figure 4. Optical micrographs of cross-sections of $\mathrm{Cu}$ coatings sprayed on: (a) steel substrate using high pressure cold spray (HPCS) system, and (b) Al substrates using low pressure cold spray (LPCS) system. Note: Both the Cu coatings are etched with $\mathrm{FeCl}_{3}-\mathrm{HCl}-\mathrm{H}_{2} \mathrm{O}$ solution. \{Reprinted by permission from, Springer International Publishing, Book, Cold-Spray Coatings: Recent Trends and Future perspectives [75]\}. 


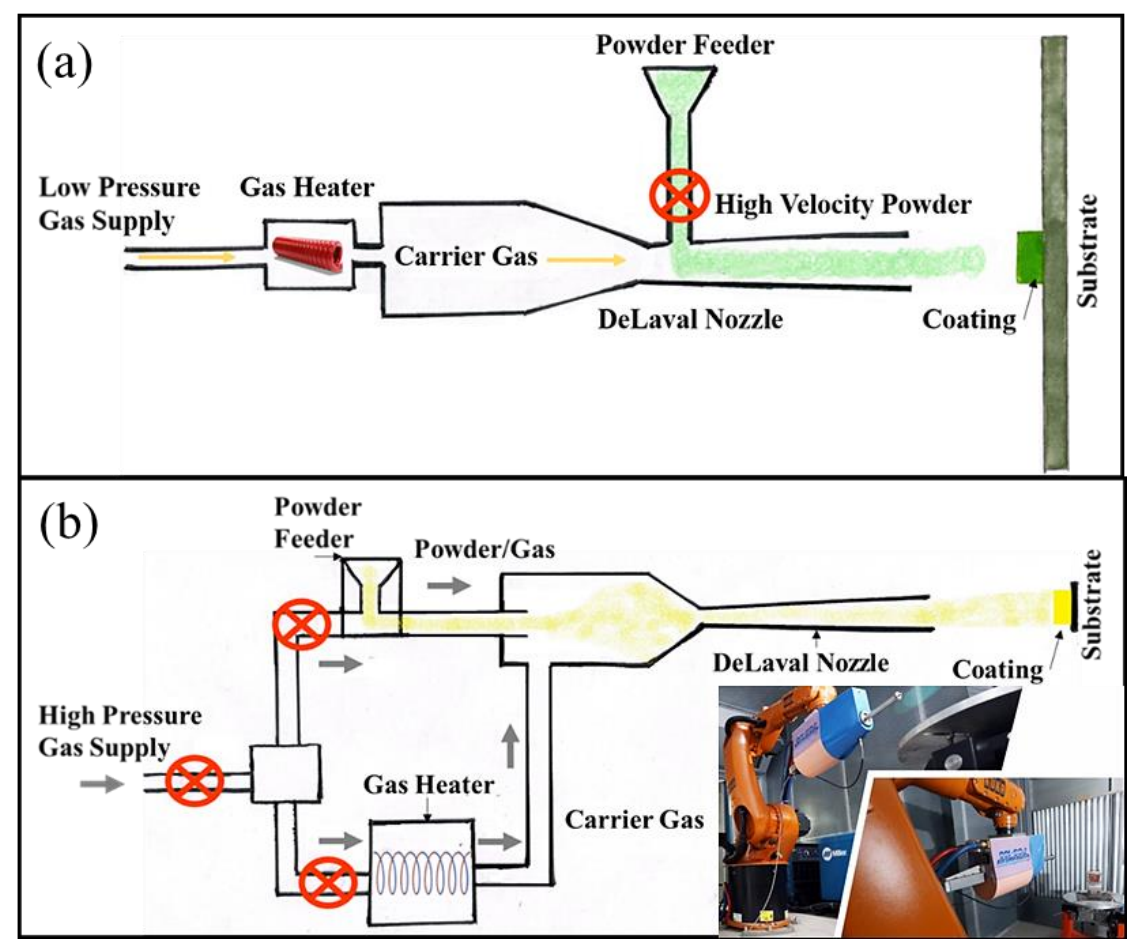

Figure 5. (a) Schematic of low pressure cold spray and (b) high pressure cold spray setup [71,75]. Inset, a high pressure cold spray system installed at Indian Institute of Technology Ropar (PCS 100, Plasma Giken, Japan).

As well, particles may rebound in LPCS due to insufficient kinetic energy. These particles bounce away from the developing CS coating and produce a peening effect that facilitates the densification of the coating (Figure 6) [12,72,75-77]. Therefore, the upper layers of the LPCS coatings generally exhibit higher porosity and are less dense compared to the coating layers that are initially formed. The shot peening phenomenon results in flattening of the splats in LPCS $[13,74,76,78]$. However, in HPCS coatings, the shot peening phenomenon is not observed since the particle velocity exceeds the critical velocity. The high velocity enables arriving particles to interact with prior-deposited layers or directly with the substrate. Hence the microstructural character of a HPCS coating exhibits lesser splat flattening that results in a higher deposition efficiency (Figure 6) [16,71,79].

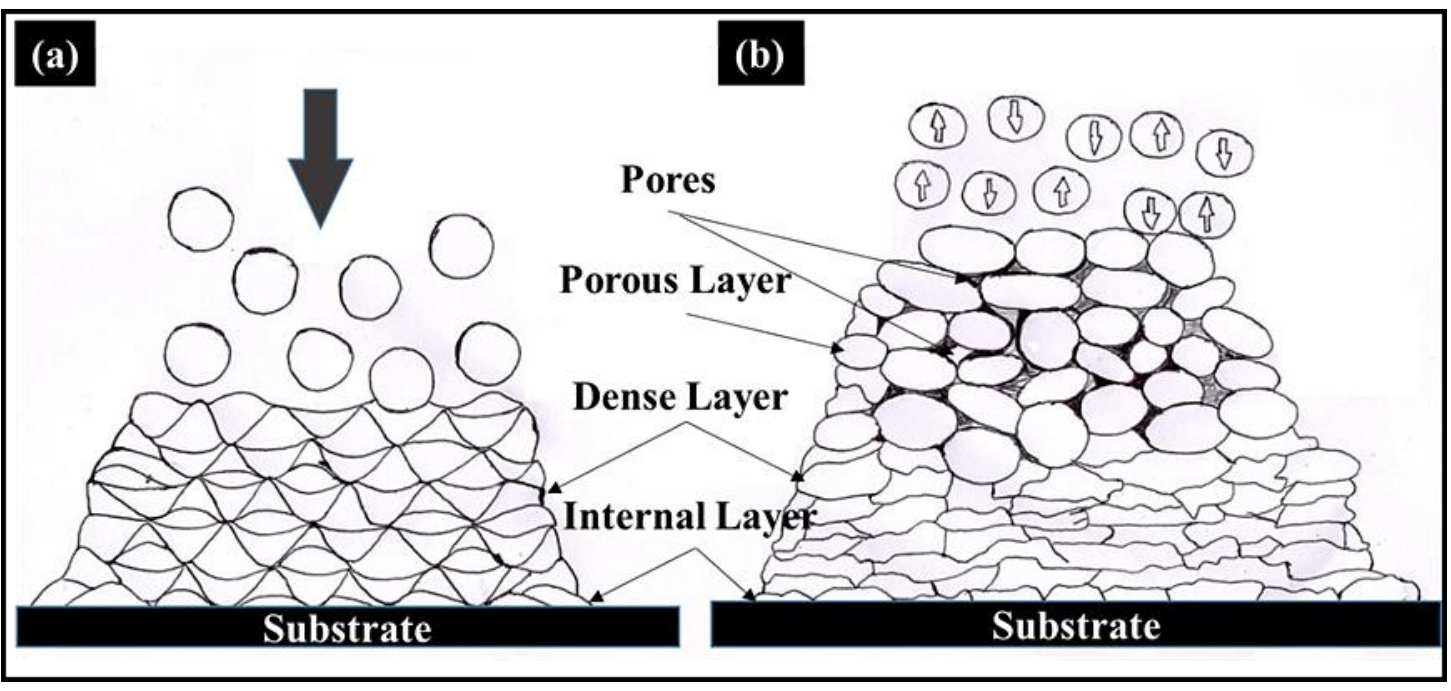

Figure 6. Schematic of the splat formation of the coatings deposited using: (a) high pressure, and (b) low pressure cold spray process. \{Reprinted by permission from, Springer International Publishing, Book, Cold-Spray Coatings: Recent Trends and Future perspectives [75]\}. 
Table 1. Operating parameters for low pressure cold spray (LPCS) and high pressure cold spray (HPCS) systems [80].

\begin{tabular}{ccc}
\hline Parameters & HPCS & LPCS \\
\hline Process Gas & $\mathrm{N}_{2}, \mathrm{He}$, Air & $\mathrm{N}_{2}$, Air \\
Gas Pressure $(\mathrm{MPa})$ & $2.5-6.0$ & $0.5-2.0$ \\
Gas Temperature $\left({ }^{\circ} \mathrm{C}\right)$ & $20-1000$ & $20-500$ \\
Gas Flow Rate $\left(\mathrm{m}^{3} / \mathrm{h}\right)$ & $50-150$ & $15-30$ \\
\hline
\end{tabular}

\section{Effect of Spray Parameters}

\subsection{Temperature}

An increase in temperature of the CS working gas also increases the gas velocity inside the nozzle (Equation (1)) [10], which increases the particle velocity. Additionally, an increase in inlet gas temperature increases the particle impact temperature. Both of these factors; increase in particle velocity and increase in particle impact temperature, lead to an increase in adhesion strength. The effect of the CS working gas (i.e., $\mathrm{N}_{2}$ ) inlet temperature on the particle $(\mathrm{Cu})$ impact temperature is depicted in Figure 7 [17].

$$
v=\sqrt{\gamma R T}
$$

where, $\gamma$ (ratio of heat capacities of gas) $=\frac{C_{P}}{C_{v}}, C_{p}$ is the gas heat capacity at constant pressure, $C_{v}$ is the gas heat capacity at constant volume, $v$ is the velocity of gas inside the nozzle, $R$ is the gas constant, and $T$ is the gas temperature at the nozzle inlet in $K$.

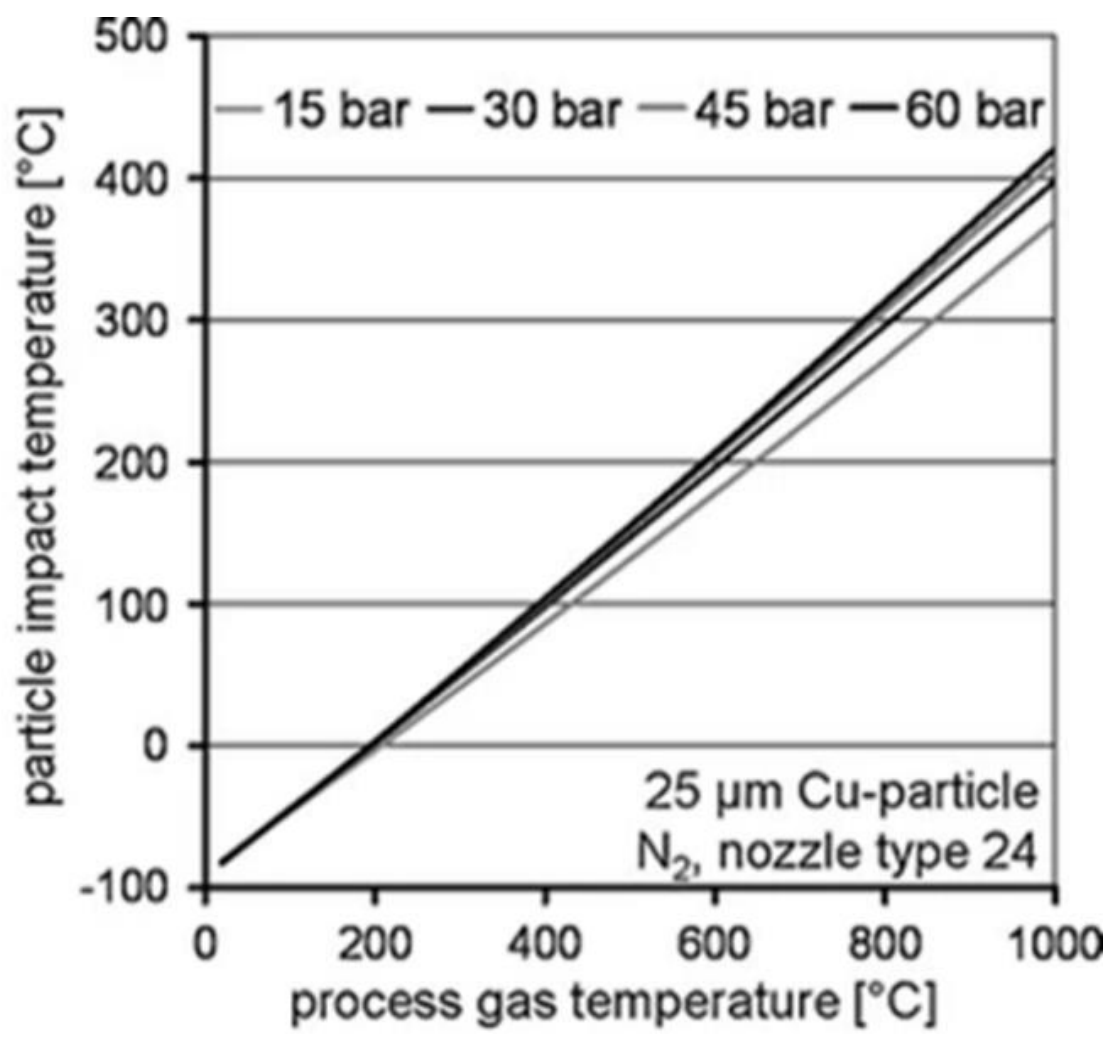

Figure 7. Effect of cold spray gas intel temperature on copper particle impact temperature with nitrogen as process gas. \{Reprinted by permission from, Springer Nature, Journal of Thermal Spray Technology, [17]\}.

A rise in particle impact temperature results in softening that facilitates particle deformation during impact, which leads to improved bonding at the interface. Assadi et al. [12] developed a relation (Equation (2)) between particle impact temperature and its critical 
velocity and found that an increase in particle temperature decreased the critical velocity of the particle.

$$
v_{c r}=667-14 \rho+0.08 T_{m}+0.1 \sigma_{U T S}-0.4 T_{P_{i}}
$$

where, $v_{c r}$ is critical velocity, $\rho$ is the density of feedstock material, $\sigma_{U T S}$ ultimate tensile strength of feedstock material, $T_{P_{i}}$ is the particle temperature at impact in $K$, and $T_{m}$ is melting temperature of the feedstock material in $K$.

However, low melting point materials such as aluminium start sticking at the nozzle's throat after an inevitable rise in the process gas temperature, leading to nozzle clogging and an undesirable decrease in deposition efficiency. Therefore, the upper limit of the temperature for attaining maximum particle velocity without nozzle clogging depends on the feedstock properties [81-84]. The optimum gas temperature for each material category to avoid nozzle clogging is a subject for further investigations.

Adachi and Ueda [85] found that an increase in temperature and pressure of the process gas increased the adhesion strength. Zahiri et al. [86] investigated that an increase in the temperature of nitrogen gas from $300^{\circ} \mathrm{C}$ to $630{ }^{\circ} \mathrm{C}$ increased the particle velocity from $610 \mathrm{~m} / \mathrm{s}$ to $765 \mathrm{~m} / \mathrm{s}$. Meng et al. [84] also reported that an increase in gas temperature enhanced the adhesion and cohesion strengths, and density of the coating. The adhesion strength of the CS coatings was increased from $56 \mathrm{MPa}$ to $73 \mathrm{MPa}$ with an increase in gas temperature from $250{ }^{\circ} \mathrm{C}$ to $500{ }^{\circ} \mathrm{C}$. Similarly, Winnicki et al. [81], Shikalov et al. [83] and Cortés et al. [87] observed similar trends in the effect of gas temperature on the coating adhesion strength.

\subsection{Pressure}

An increase in pressure of the process gas increases the acceleration rate of the particles in the nozzle, enabling the particles to attain significantly high velocities before leaving the nozzle [81]. Therefore, an increase in pressure of the process gas yields high energy impact of particles at the substrate, which enhances mechanical interlocking and promotes metallurgical bonding at the particle-substrate and particle-particle interfaces [82]. Furthermore, higher energy impact results in deeper penetration of the particles into the substrate and the consecutive layers. Ultimately, an increase in pressure of the process gas results in enhanced cohesion strength, adhesion strength, density and mechanical properties of the coating $[77,81,88]$. Moreover, a pressure increase enhances the impact conditions at the substrate and results in higher deposition efficiency [73,86].

Ning et al. [80] investigated the effect of process gas pressure on the deposition of $\mathrm{Al}$ particles on a Ni substrate (soft-on-soft) using a LPCS system. The authors observed that an increase in gas pressure from 0.7 MPa to 2.4 MPa increased the adhesion strength from $40 \mathrm{MPa}$ to $70 \mathrm{MPa}$. Low gas pressure resulted in severe plastic deformation of Al particles and induced a peening effect on the substrate. However, particles at higher gas pressure penetrated deep into the substrate without exhibiting any significant plastic deformation. After annealing, the deeply penetrated particles formed a broader intermetallic layer, while severely deformed particles formed a thin intermetallic layer at the interface. Therefore, higher adhesion strength was observed for HPCS than for LPCS depositions. Similar observations were reported by Xie et al. [31] and Luo et al. [89] in considering the deposition of $\mathrm{Ni}$ on an $\mathrm{Al}$ substrate and Ti on a Ti6Al4V substrate, respectively. Thus, an increase in gas inlet pressure enhances the formation of intermetallic phases at the interface during post heat treatment of the as-sprayed coatings [72,90].

\subsection{Process Gas}

The process gas, also called the working gas, and its temperature influence the coating properties to a greater extent. Inert gases such as nitrogen or helium are used for HPCS, and compressed air or nitrogen are employed for LPCS. Pure nitrogen gas is commonly preferred due to its low cost and availability. Helium is several times more expensive than nitrogen; nevertheless, it has found a niche in the high efficiency deposition of high quality coatings of materials that are difficult to spray; such as steel, titanium and its alloys, nickel, 
and metal-matrix ceramics [86]. However, helium is less dense than nitrogen, corroborating its faster consumption during CS operation. Thus, helium increases the running cost, but this is somewhat compensated with a reduced spray time. The effect of process gas on the CS coating properties has been documented [85,91,92].

Tan et al. [91] deposited Ti6Al4V onto a Ti6Al4V substrate using helium and nitrogen as the process gases. They observed that helium resulted in coatings with a denser microstructure and higher adhesion strength owing to the more severe deformation of the Ti64 particles when helium is the working gas. Similar results were reported by Khun et al. [93].

\section{Effect of Spray Torch Conditions}

\subsection{Stand-Off-Distance}

The distance from the nozzle exit to the substrate surface is termed as the stand off distance (SoD), which is a crucial factor that determines the interfacial properties of cold sprayed coatings [94]. Two essential conditions should be satisfied to optimize the SoD. Firstly, the substrate must be placed at a SoD where bow shock must be disappeared. Secondly, the substrate must be placed at a SoD where gas velocity can remain higher than the particle velocity during impact (positive drag force) [69]. Several investigators have optimized the SoD to achieve high-quality coatings for different feedstocks and process gases $[69,95]$. Feng et al. [96] investigated the effect of SoD on the quality of CS NiCoCrAlY coatings. They reported non-uniform coating thickness at a SoD of $50 \mathrm{~mm}$; while a homogeneous coating with uniform thickness was obtained at a SoD of $25 \mathrm{~mm}$. The oxygen content in the coating was $1.3 \%$ in the latter case, whereas it was more than $3 \%$ at the greater SoD. The best combination of coating properties was achieved at an optimum SoD of $20 \mathrm{~mm}$ [94]. Similar results were achieved by Adachi et al. [85].

\subsection{Spray Torch Traverse Speed}

Spray torch traverse speed determines the coating thickness per pass and the time between two passes. CS coatings are built up in two stages, which is common to thermal spray processes in general. In the first CS stage, particles interact with the substrate to build an initial coating layer. In the second stage, consecutive layers are composed of the interaction of striking particles with pre-deposited layers. The first stage interaction between the particles and the substrate governs the quality of the interface, which determines the adhesion strength of the coating. The second stage of interaction governs the intrinsic properties of the deposited coating [97] that give rise to cohesion properties. The torch traverse speed influences both stages of coating development; hence it is a crucial factor that must be optimized.

Rezaeian et al. [98] investigated the effect of torch traverse speed on the bond strength of CS Ti on Ti6Al4V substrate. They observed that the bond strength deteriorated with a decrease in torch traverse speed. Similar results were obtained by Tan et al. [99] for the same interface and reported that an increase in traverse speed (from $100 \mathrm{~mm} / \mathrm{s}$ to $500 \mathrm{~mm} / \mathrm{s}$ ) reduced the number of particles impacting the substrate, which allowed the dynamic deformation of particles governed by ASI, leading to better bonding at the interface. Additionally, the torch traverse speed has a significant influence on the oxide layer formation during deposition, which needs to be explored further.

\subsection{Spray Angle}

The effect of spray angle on the bonding mechanism of conventional thermal spray processes has been explored extensively. However, limited work is available on this aspect in the context of CS. The relationship between the bonding mechanism and the spray angle is expected to be different for CS than that for other thermal spray processes $[100,101]$. According to the ideal conditions, as reported by Karthikeyan [102], the CS nozzle should be focused perpendicular to the substrate throughout the deposition to obtain the highest particle energy impact against the substrate, which would derive high-quality coatings. However, it is not feasible to consistently carryout CS at an orthogonal angle with respect 
to the substrate surface since the majority of engineering components possess complex geometries. Therefore, it is pertinent to investigate the effect of spray angle on deposition mechanism and the associated coating properties.

Yin et al. [103] investigated the effect of spray angle (60, 75, and 90 degrees) on particle deformation and quality of a Ti coating. It was noticed that at a tilted position of spray torch, the particles deformed locally on one side owing to the tangential momentum. This one-sided localized deformation increased with a further decrease in spray angle, leading to poorer particle deposition. As well, adhesion strength, coating thickness, density and mechanical properties deteriorated with respect to decreasing the CS angle from 90 to 75 degrees.

Loke et al. [30] observed the highest adhesion strength of Al6061 alloy on Al6061 alloy at a spray angle of $60^{\circ}$ (Figure 8 ) and attributed this behavior to higher compressive residual stresses. However, a marginal change $(9 \%)$ in adhesion strength was obtained for the coatings deposited with spray angles in the range $40-80^{\circ}$. The highest mean adhesion strength was $58 \mathrm{MPa}$ obtained with a spray angle of $60^{\circ}$ compared with the lowest value of $53 \mathrm{MPa}$ obtained with a spray angle of $80^{\circ}$. However, the mean adhesion strength (58 MPa) of coatings obtained with spray angle of $60^{\circ}$ was $29 \%$ higher than the mean adhesion strength $(41 \mathrm{MPa})$ obtained with spray angle of $90^{\circ}$. This work contradicts the findings of earlier investigations that indicated a perpendicular position of the torch as an optimum spray position. Hence, the effect of spray angle on the adhesion strength of CS coatings is not completely resolved or understood, and further investigation is warranted.

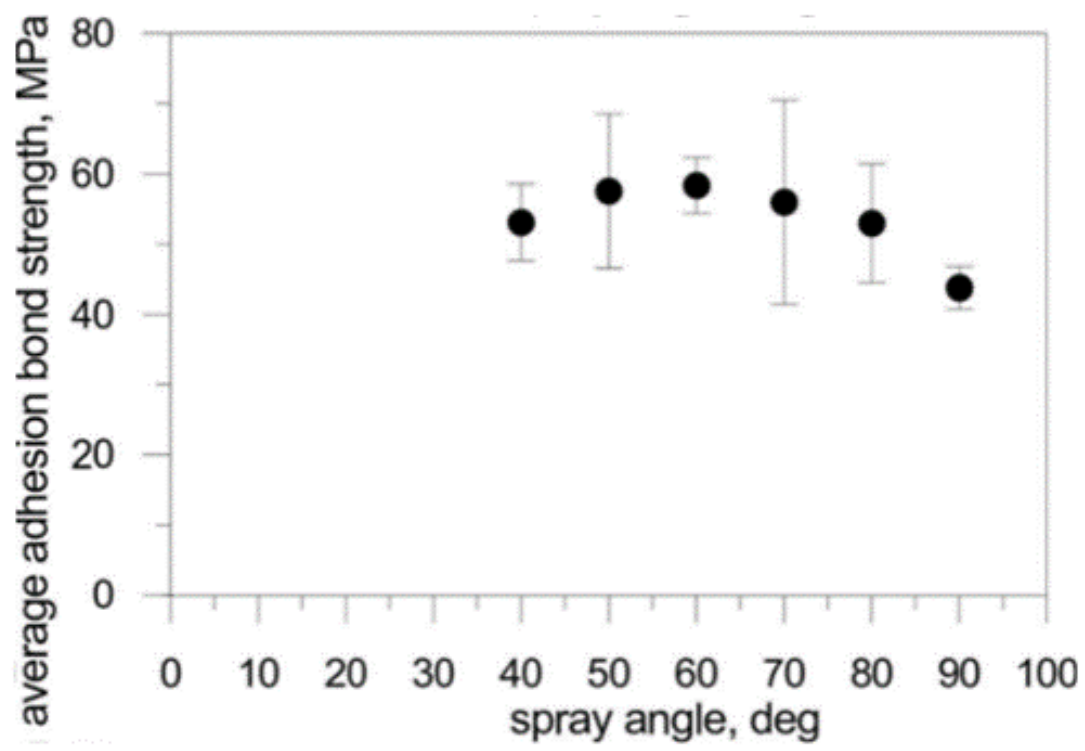

Figure 8. Comparison of average adhesion strength of $\mathrm{Al}$ alloy coatings on $\mathrm{Al}$ alloy substrates cold sprayed at angles from $40^{\circ}$ to $90^{\circ}$. \{Reprinted by permission from, Springer Nature, Journal of Thermal Spray Technology, [30]\}.

\section{Effect of Feedstock Conditions}

\subsection{Morphology}

Two particle morphologies are used in CS; these being irregular and spherical. Particles with an irregular morphology present a higher mean particle velocity than spherical morphology of the same average particle size due to their higher drag coefficients than spherical particles. However, a spherical morphology is preferred to achieve better adhesion strength and denser coating microstructures [46]. Spherical particles penetrate deeper inside the substrate and undergo the phenomenon of jet formation, which leads to higher adhesion strength. Irregular particles, on the other hand, create an inhomogeneous interface and insufficient deformation that gives rise to lower adhesion strengths [104]. Irregular particles strike the substrate on their sharper side due to considerations of fluid 
dynamics. These particles tend to deform by adapting to the surface topography instead of penetrating into the substrate [51,105].

Ning et al. [80] found that particles with irregular morphology experience $20-50 \mathrm{~m} / \mathrm{s}$ higher in-flight velocity than those with the same average particle size but of spherical morphology. Wong et al. [106] observed similar trends.

\subsection{Size}

In CS, high particle velocity results in greater adhesion strength of the coating. Smaller particles experience higher in-flight accelerations owing to their lower mass $[42,68]$ and attain higher velocity at the nozzle exit than the larger particles. On the other hand, since the larger particles have a lesser surface-to-volume ratio, they retain heat for a longer time; which catalyzes ASI that leads to better bonding at the interface $[42,68,96]$. Another consideration is that smaller particles experience a stronger bow-shock effect than larger particles, which reduces their impact energy [63]. Therefore, an optimum particle size is necessary to develop high-quality coatings with regard to coating properties and adhesion strength $[42,51,68,96,107]$.

Wang et al. [108] also investigated the effects of ceramic particle size on deposition efficiency and corrosion behavior of CS SiCp/ Al 5056 composite coatings. Both deposition efficiency and corrosion resistance were highest for an average particle size of $20 \mu \mathrm{m}$. Feng et al. [96] found that 5 50 $\mu \mathrm{m}$ size particles resulted in the best physical and mechanical properties for NiCoCrAlY coatings. Adachi and Ueda [85] concluded that a particle size of 5-20 $\mu \mathrm{m}$ results in a denser SS 316L coating microstructure than CS coatings formed from $10-45$ and $20-53 \mu \mathrm{m}$ feedstock. Elsenberg et al. [109] indicated that particle size exhibited a limited effect on deposition behavior; however, it was noted that larger particles of harder material increased erosion of the pre-deposited layers.

\subsection{Material}

The feedstock material has a significant influence on the deposition mechanism of the particles. Soft particles deform more severely than hard particles and result in better adhesion strength. Hard particles cause erosion of the substrate, while soft particles deform over the substrate without causing erosion [110]. Additionally, the hardness of the substrate also plays a significant role in the adhesion mechanism. For instance, a soft-on-soft interface results in a better adhesion strength that is attributed to jet formation. A schematic of different particle substrate hardness combinations is represented in Figure 9 [71].

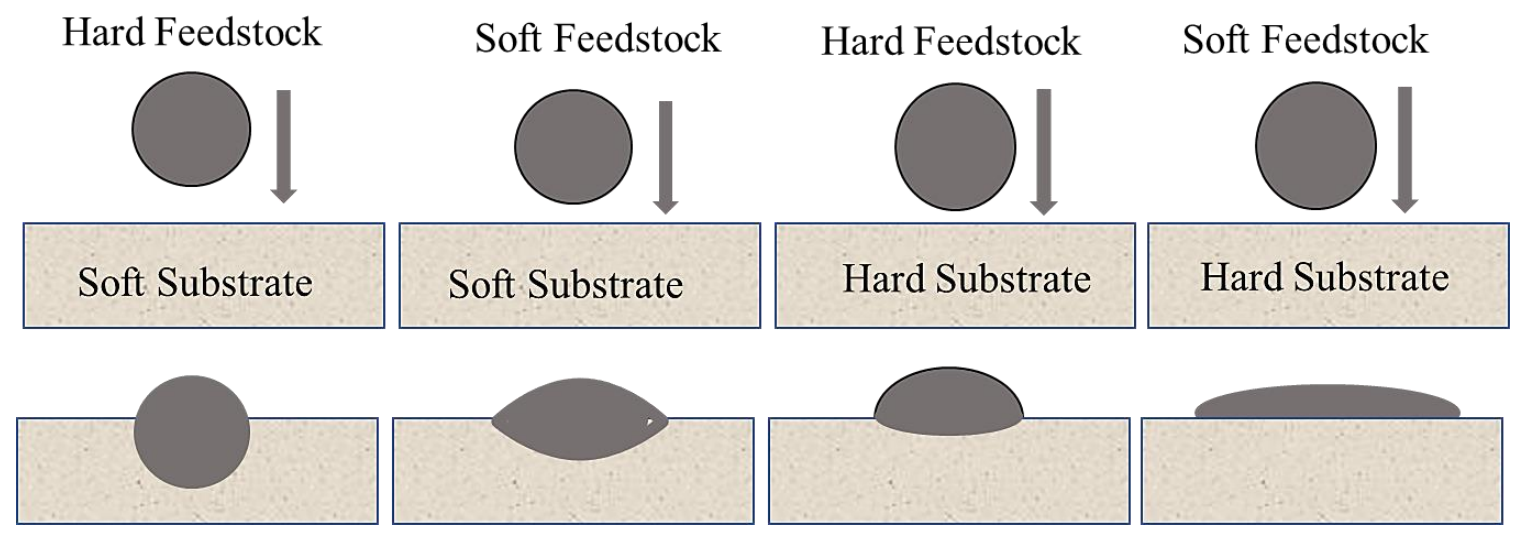

Figure 9. A schematic represents the impact behavior of different particle-substrate hardness combinations [71].

Go et al. [110] investigated the impact behavior of three feedstock materials; i.e., $\mathrm{Ti}_{2} \mathrm{AlC}, \mathrm{Cr}_{2} \mathrm{AlC}$, and $\mathrm{Ti}_{3} \mathrm{SiC}_{2}$. An increase in the process gas temperature resulted in increased adhesion strength for $\mathrm{Ti}_{2} \mathrm{AlC}$ and $\mathrm{Cr}_{2} \mathrm{AlC}$ coatings due to the materials' thermal softening. However, $\mathrm{Ti}_{3} \mathrm{SiC}_{2}$ being a harder ceramic, resulted in high compressive 
strength even with the highest attainable temperature of the CS system; hence limiting the deformability of this particular material.

Nikbakht et al. [105] found that multiple splats of dissimilar material particles experienced higher deformation than similar material particles. Higher deformation of dissimilar material caused better grain refinement at inter-splat and splat-substrate interfaces. The deposition efficiency for the Ni-Ti feedstock mixture at $500{ }^{\circ} \mathrm{C}$ gas temperature was $30 \%$, however, the individual deposition efficiencies of each $\mathrm{Ni}$ and Ti feedstocks were $10 \%$ and $40 \%$, respectively. Therefore, it was proposed that critical velocity for the Ni-Ti feedstock mixture is different from the individual critical velocities of each $\mathrm{Ni}$ and Ti feedstocks.

\section{Effect of Substrate Conditions}

The adhesion strength of CS coatings with the substrate is not only based on mechanical interlocking. It is determined also by adiabatic shear instability, plastic deformation of the colliding materials and static recrystallization $[45,64,66,111,112]$. All these factors are attributable to substrate conditions such as hardness, material chemistry, surface roughness and temperature of the substrate.

\subsection{Surface Roughness}

The surface roughness of the substrate plays a prominent role in the bonding mechanism at the interface. However, there are contradicting reports on the effect of substrate roughness concerning adhesion for soft-on-soft interfaces. For instance, Hussain [16] reported that smoother substrate surfaces are best for good adhesion strength, whereas, Ghelichi and Guagliano [113] had a conflicting report. Similarly, Kumar et al. [54] found that semi-polished substrates were ideal for achieving the best adhesion for a $\mathrm{Cu}$ on steel combination.

Singh et al. [63] obtained better adhesion for mirror-finished substrates than semipolished and as-received substrates for the same material combinations. The surface roughness were (i) Ra $6 \mu \mathrm{m}$ for as-received, (ii) Ra $0.5 \mu \mathrm{m}$ for semi-polished, and (iii) Ra $0.06 \mu \mathrm{m}$ for mirror-finished. The authors found that surface asperities and waviness of the asreceived substrate caused gap at the interface (Figure 10a) resulting in poor adhesion. Furthermore, the energy of the particles was dissipated in deforming the sharper peaks of the semi-polished surface, which hindered particle penetration into the substrate and induced a gap at the interface; hence resulting in poor adhesion (Figure 10b). No similar surface asperities and peak hindrances were observed in the case of mirror-finished substrates, and the particles intruded into the substrate, which resulted in the highest adhesion strength (Figure 10c,d). Additionally, surface asperities and waviness of the as-received substrate caused spray angle variations which also resulted in lesser adhesion strength (Figure 11) than the mirror-finished substrate. Similar trends in adhesion strength were observed by Theimer et al. [114] for brass on steel combinations.

\subsection{Material}

The substrate material significantly influences the interfacial interactions and phase transformations. Chu et al. [115] investigated the effects of Fe particles on polished substrates of SS 316L, Fe, and composite $90 \mathrm{Fe}(90 \% \mathrm{Fe}$ and 10\% 316L). They found that deposition efficiency of Fe on $90 \mathrm{Fe}$ was highest among all three substrates; however, no specific mechanism was offered to explain this finding.

Wustefeld et al. [41] proposed a novel adhesion mechanism for CS for Al coatings onto AlN substrates that demonstrated excellent adhesion strength. The Al-Al lattice planes of $\mathrm{Al}$ splats showed a similar crystal orientation with Al-Al lattice planes of AlN substrate. Therefore, the atomic planes of the Al splats (111) were developed in continuation with the atomic planes of the AlN substrate (0001) as demonstrated in Figure 12 [116]. The phenomenon is termed as 'local heteroepitaxy'. Grain refinement increased the local heteroepitaxy owing to the intrinsic mobility of $\mathrm{Al}$ atoms of the splats, which aligned splat- 
substrate lattice planes. Drehmann et al. $[19,116]$ have also reported a similar heteroepitaxy adhesion mechanism at $\mathrm{Al} / \mathrm{ZrO}_{2}$ interfaces.

Additionally, Drehmann et al. [116] found that substrates with higher thermal conductivities exhibit higher adhesion strength, which could be attributed to higher atomic mobility at the interface. Additionally, the high conductivity of the substrate minimized the thermal residual stresses at the interface and was attributable to a reduced impact temperature. The influence of substrate materials and their thermal conductivities on residual stresses and adhesion strength is represented in Figure 13.

Ko et al. [50] proposed another adhesion mechanism for CS copper onto AlN substrate, and $\mathrm{Al}$ onto $\mathrm{ZrO}_{2}$ substrates. A nanometer thin amorphous zone was observed near the interface and was attributed to atomic intermixing of the coating and substrate. A higher thickness of amorphous zone was observed for the $\mathrm{Cu}$-AlN interface in comparison to the $\mathrm{Al}-\mathrm{ZrO}_{2}$ interface. It was suggested that the high impact energy of denser $\mathrm{Cu}$ particles gives rise to a higher bond strength for the $\mathrm{Cu}$-AlN interface. This proposed intermixing phenomenon is applicable universally to soft-on-hard interfaces. Other factors that would influence the intermixing zone are the relative densities of the CS particles and substrate and the impact velocity.

In addition, Singh at al. [62,118] explored the influence of an electroplated SS 316L steel substrate on the adhesion strength of CS copper coatings. Cu-electroplated substrates resulted in poor adhesion strength, however, significant improvement in adhesion strength was observed for Ni-electroplated substrate compared to the bare steel substrate.

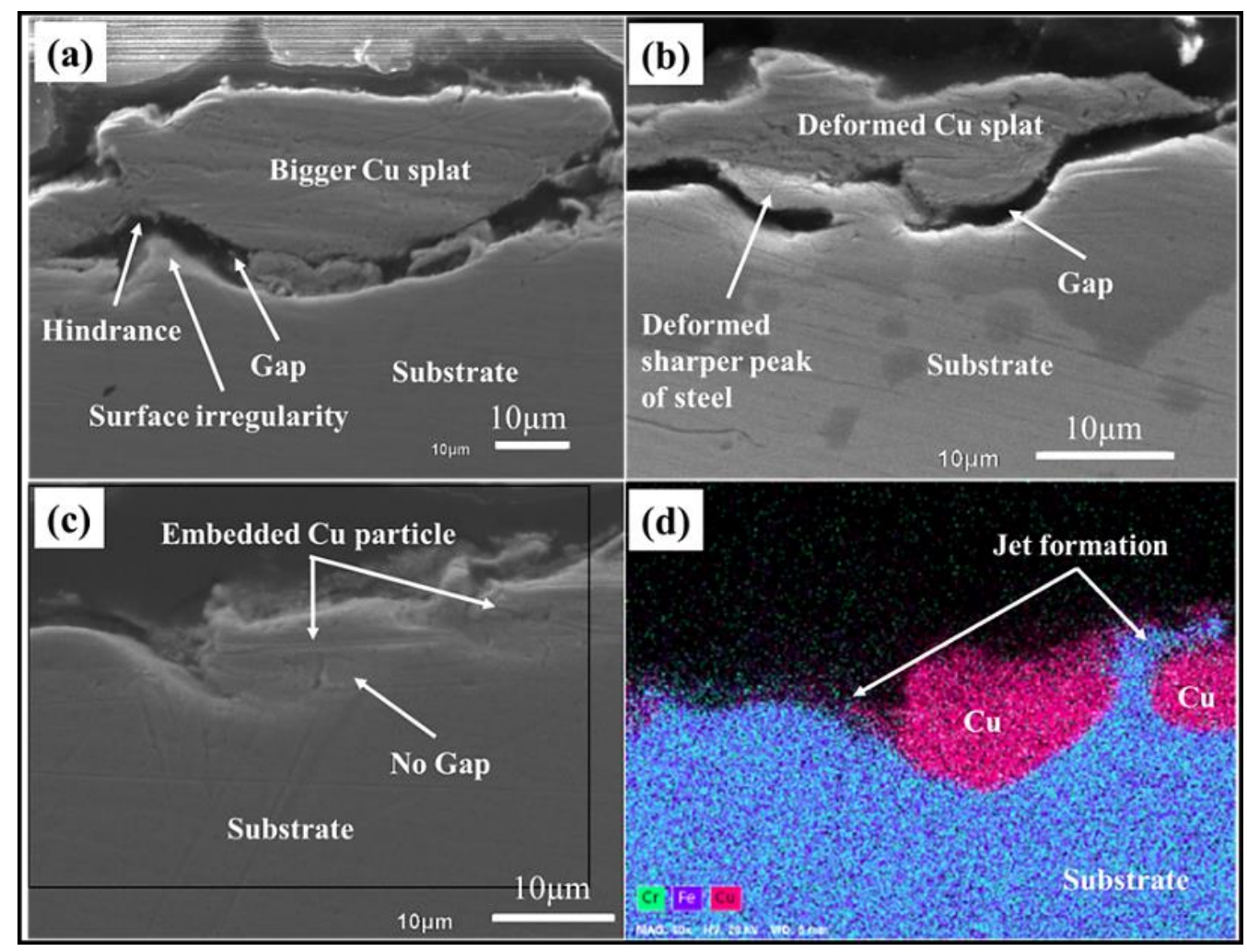

Figure 10. Cross-sectional SEM analysis of the high pressure cold sprayed single copper particles deposited on (a) as-received, (b) semi-polished, and (c) mirror-finished SS316L steel substrates, (d) EDS analysis of (c). \{Reprinted by permission from, Taylor \& Francis, Surface Engineering, [63]\}. 


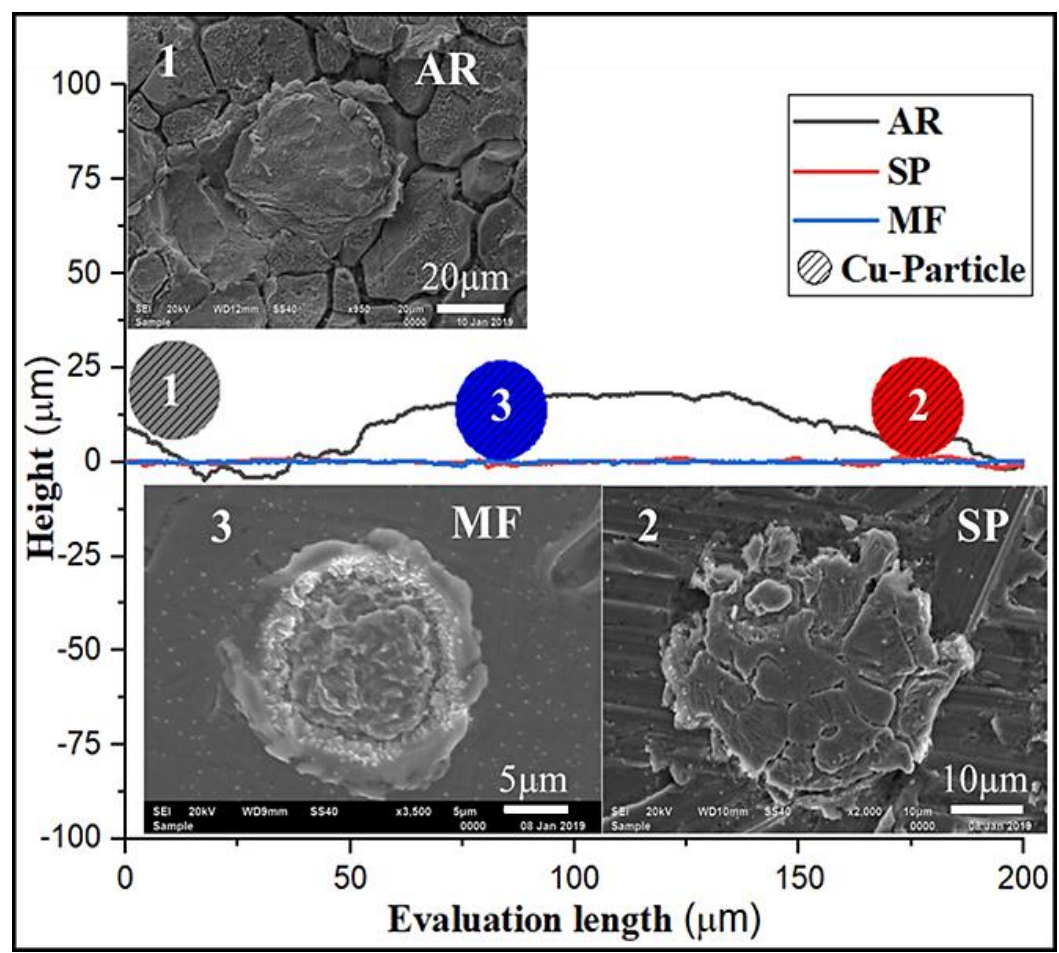

Figure 11. Surface profiles of SS 316L steel substrates and their respective SEM micrographs showing single copper particle impingements. $\mathrm{AR}=$ as-received, $\mathrm{MF}=$ mirror-finished, $\mathrm{SP}=$ semi-polished. \{Reprinted by permission from, Taylor \& Francis, Surface Engineering, [63]\}.

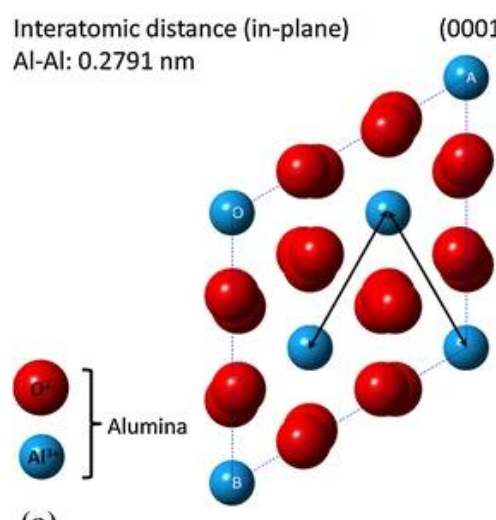

(a)
Interatomic distance (in-plane) Al-Al: $0.2864 \mathrm{~nm}$
(111)
Lattice misfit: 2,6\%

(c)

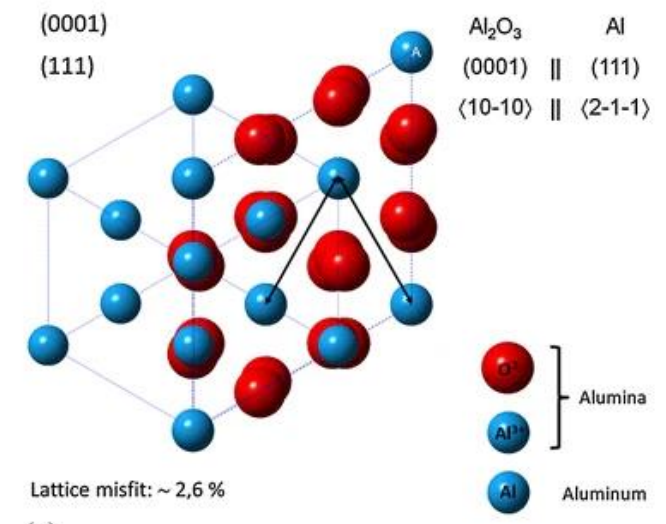

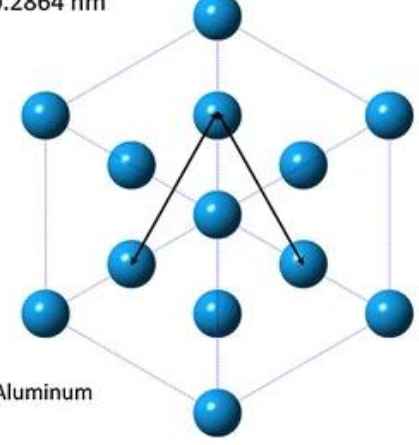

(b)

Figure 12. (a) Representing atomic (0001) plane and $\mathrm{Al}$ - $\mathrm{Al}$ interatomic distance of the $\mathrm{Al}_{2} \mathrm{O}_{3}$ lattice, (b) (111) plane and interatomic distance (Al-Al) of the Al lattice, (c) minimal lattice misfit for parallel lattice directions. \{Reprinted by permission from, Springer Nature, Journal of Thermal Spray Technology [117]\}. 

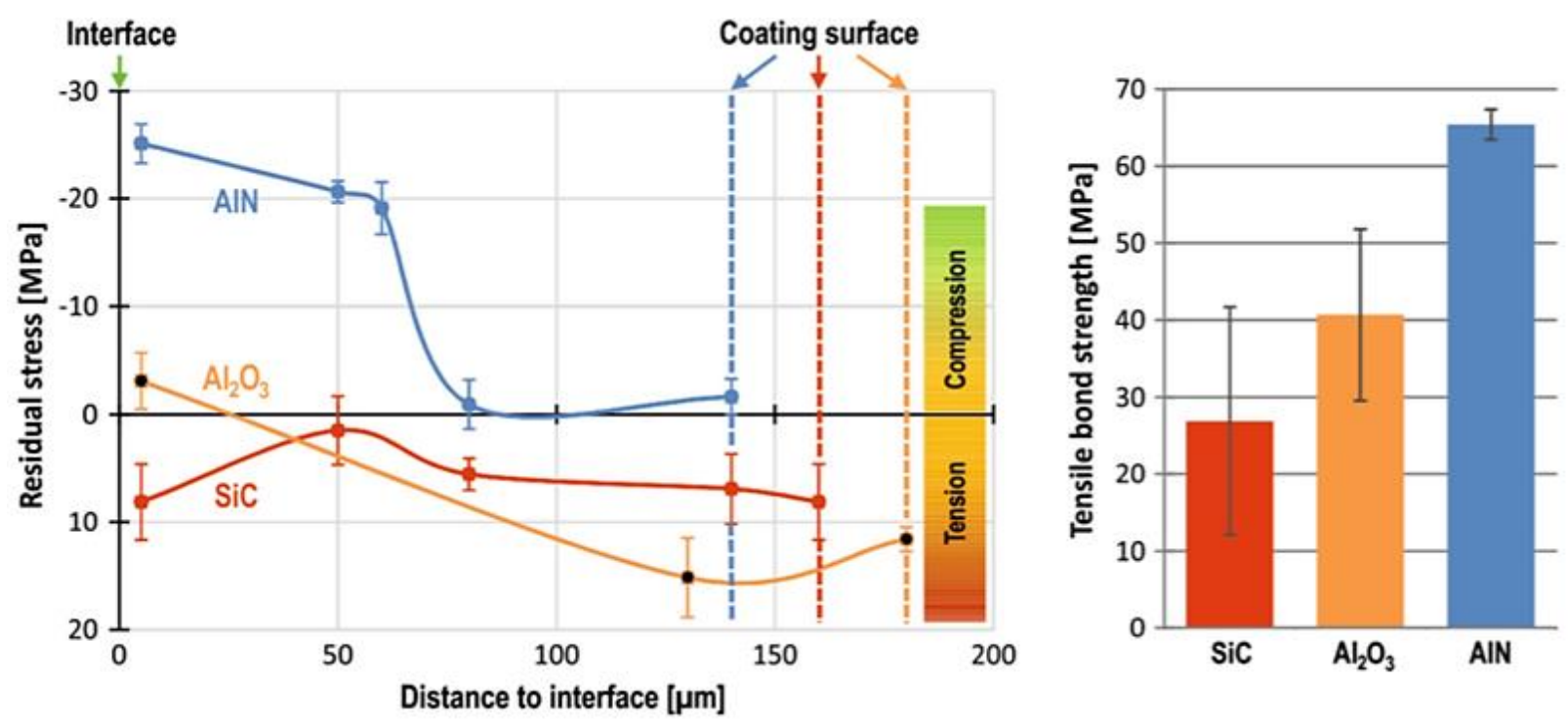

Figure 13. (Left); representing the effect of thermal conductivity of substrates on the residual stresses near the interface, and (right); effect of each substrate material on adhesion strength of the Al coatings. \{Reprinted by permission from, Springer Nature, Journal of Thermal Spray Technology, [116]\}.

\subsection{Substrate Hardness}

In CS, deformation of the substrate facilitates ASI and jet formation $[48,103]$. The formation of jets results in mechanical and metallurgical bonding at the interface. Soft substrates (e.g., $\mathrm{Al}, \mathrm{Cu}$ ) are susceptible to higher deformation than hard substrates (e.g., ceramics, steels), hence, results in a better adhesion strength [51,62]. Studies have been made to attain good adhesion strength for hard substrates, out of which, substrate pre-heating is the most common strategy. However, Singh et al. $[62,118]$ found that electroplating of the SS 316 substrate with a softer material such as Ni improved the adhesion strength of CS $\mathrm{Cu}$ coatings. Furthermore, Perton et al. [119] applied laser heat treatment prior to CS to improve the adhesion strength by reducing the substrate hardness.

Wang et al. [107] found that a hard steel substrate induced high deformation onto the striking $\mathrm{Al}$ particles, which improved the cohesive strength in the coating nearer to the substrate. However, hard particles $\left(\mathrm{Al}_{2} \mathrm{O}_{3}\right)$ were embedded inside the soft $\mathrm{Al}$ substrate, which led to strong interfacial bonding. Therefore, it can be concluded that the substrate hardness influences the coating properties significantly in the vicinity of the interface.

Wang et al. [120] found that softer substrates resulted in higher deposition efficiency, better cohesion strength, higher hardness and lower porosity; all of which were attributed to the higher impact temperature of the particle-substrate interface. The higher interfacial temperature facilitated metallurgical bonding that was identified from development of $\sim 5 \mu \mathrm{m}$ adiabatic shear bands along the interface.

\subsection{Substrate Pre-Heating}

Pre-heating of the substrate influences the bond strength of the CS deposits for softon-hard and hard-on-hard interfaces. It has a negligible effect on the bonding strength of soft-on-soft and hard-on-soft interfaces [25,64,111,121-126]. Pre-heating induces softness to the substrate surface, which facilitates deformation of the substrate during the impact of the particles, resulting in jet formation and better bonding strength $[112,127,128]$.

Perton et al. [119] applied laser ablation to pre-heat the substrate before depositing Ti-alloy. The laser ablation of the substrate smoothened the surface, which enhanced the adhesion strength at the interface. Watanabe et al. [124] reported that adhesion strength of CS combinations of (i) $\mathrm{Cu}$ on A5083, (ii) $\mathrm{Cu}$ on $\mathrm{Fe}$, and (iii) $\mathrm{Fe}$ on $\mathrm{Cu}$ improved by pre-heating the substrate since there was relief of thermal stresses. Goldbaum et al. [129] 
observed an increase in recrystallization at the splat boundaries and splat-substrate interface due to substrate pre-heating, which increased both cohesion and adhesion strength of the CS coatings. Nastic et al. [128] found that the adhesion strength of $\mathrm{CS}_{\mathrm{TiO}_{2}}$ on Ti substrate decreased from $1.35 \mathrm{MPa}$ to $0.49 \mathrm{MPa}$ with an increase in substrate temperature from $100{ }^{\circ} \mathrm{C}$ to $200^{\circ} \mathrm{C}$ owing to the formation of a thicker oxide layer.

Furthermore, Drehmann et al. [116] investigated the effect of substrate pre-heating on the adhesion strength of Al particles on an AlN substrate. As-sprayed specimens were subsequently annealed to further enhance the adhesion strength. Adhesion strength increased with an increase in the temperature of the AlN substrate prior to spray. An additional thermal energy input due to pre- and post-spray heating induced atomic mobility at the Al-AlN interface. Additionally, deformation-induced recrystallization (Figure 14) near the interface facilitated atomic mobility. Atomic mobility at the interface minimized the grain orientation misfit of the coating material with the substrate; hence resulting in better adhesion strength.
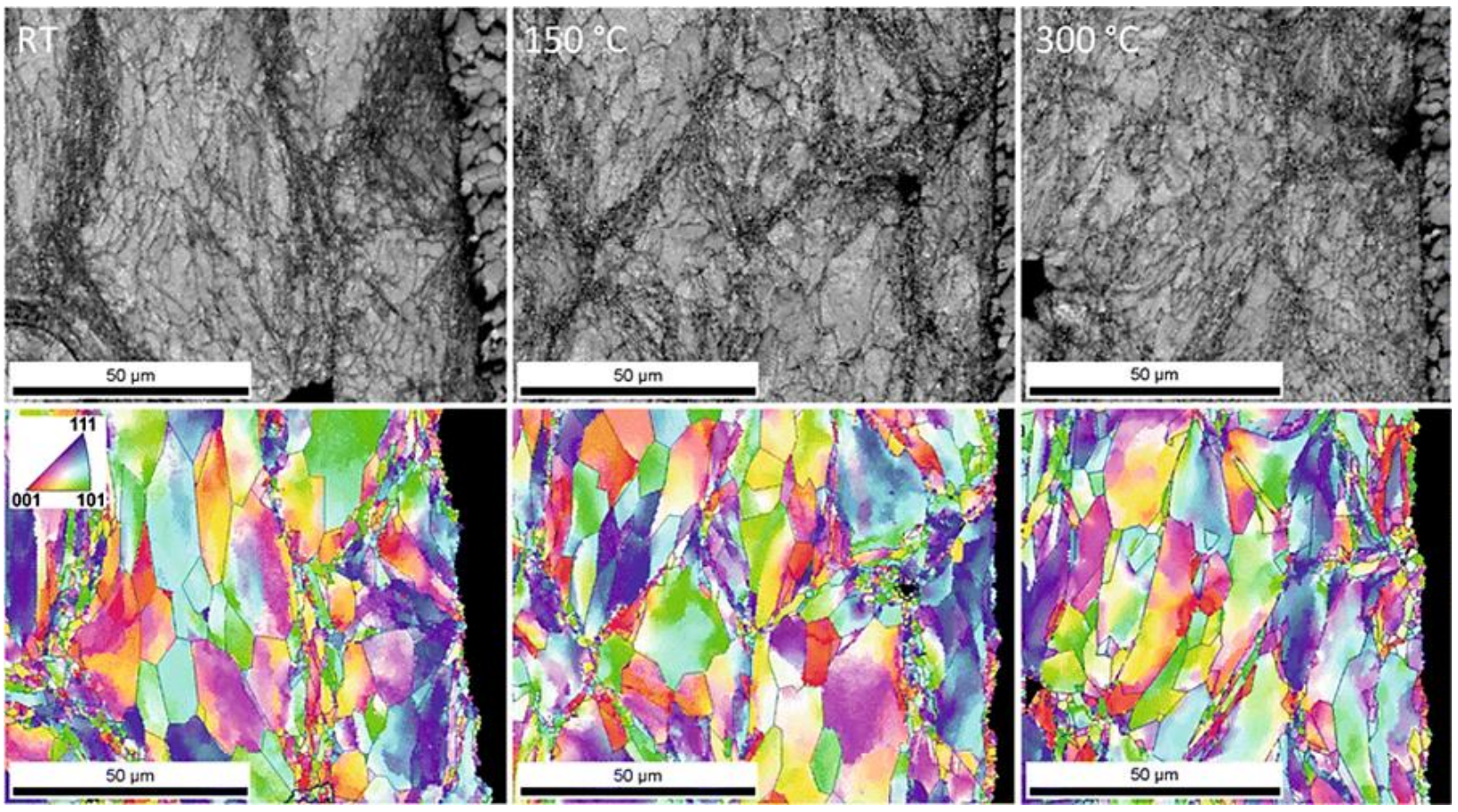

Figure 14. SEM and EBSD images of cold sprayed Al on ALN substrate representing recrystallization at the particle-particle and particle substrate interfaces in relation to substrate pre-heating temperature \{Reprinted by permission from, Springer Nature, Journal of Thermal Spray Technology, [116]\}.

\subsection{Oxide Layer Thickness}

The literature indicates that bonding in CS is governed by mechanical interlocking and metallurgical bonding. Severe plastic deformation at the interface, owing to the high energy impacts of the particles, break the native oxide layers of the interacting surfaces. The disruption of oxide layers facilitates the penetration of particles into the substrate, which leads to jet formation and mechanical interlocking.

Metallurgical bonding is manifested due to chemical interchange at the interface that is attributed to thermal softening caused by ASI [34]. Additionally, the formation of jets cleans the broken oxides and instigates direct contact of particles against the substrate, which facilitates metallurgical bonding. The critical velocity required to break the oxide layer increases with the thickness of the oxide layer. Ichikawa and Ogawa [66] investigated that an increase in oxide layer thickness from 0 to $0.35 \mu \mathrm{m}$ decreased the deposition efficiency from $55 \%$ to $0.03 \%$. Christoulis et al. [45] demonstrated that either removal of the native oxide layer or transformation of it into an amorphous oxide layer is required to achieve 
effective bonding at the interface. Hassani-Gangaraj et al. [18] also reported that the native oxide layer breakage facilitates metallurgical bonding. As well, unstable jets form on impact and fragment surface asperities which is favorable for metallurgical bonding.

Ichikawa et al. [35] used auger spectroscopy to determine the presence of oxides at the fractured surfaces of a $\mathrm{Cu}$ splat onto an $\mathrm{Al}$ substrate after adhesion testing. A pictorial view of the study is presented in Figure 15. Adhesion strength was predicted to be lesser at the center and stronger near the edges of the splats owing to the presence of an unbroken oxide layer near the center of the splats. Similar outcomes were found by Rahmati et al. [130] by employing a numerical approach to explore the effect of oxide layer on adhesion strength of $\mathrm{CS} \mathrm{Cu}$ on $\mathrm{Cu}$. It was demonstrated [131] that breakage of the native oxide layer from the particle and substrate allowed direct elemental contact between the particle and substrate; hence resulting in metallurgical bonding. It was also validated that a higher critical velocity was required for a thicker oxide layer.

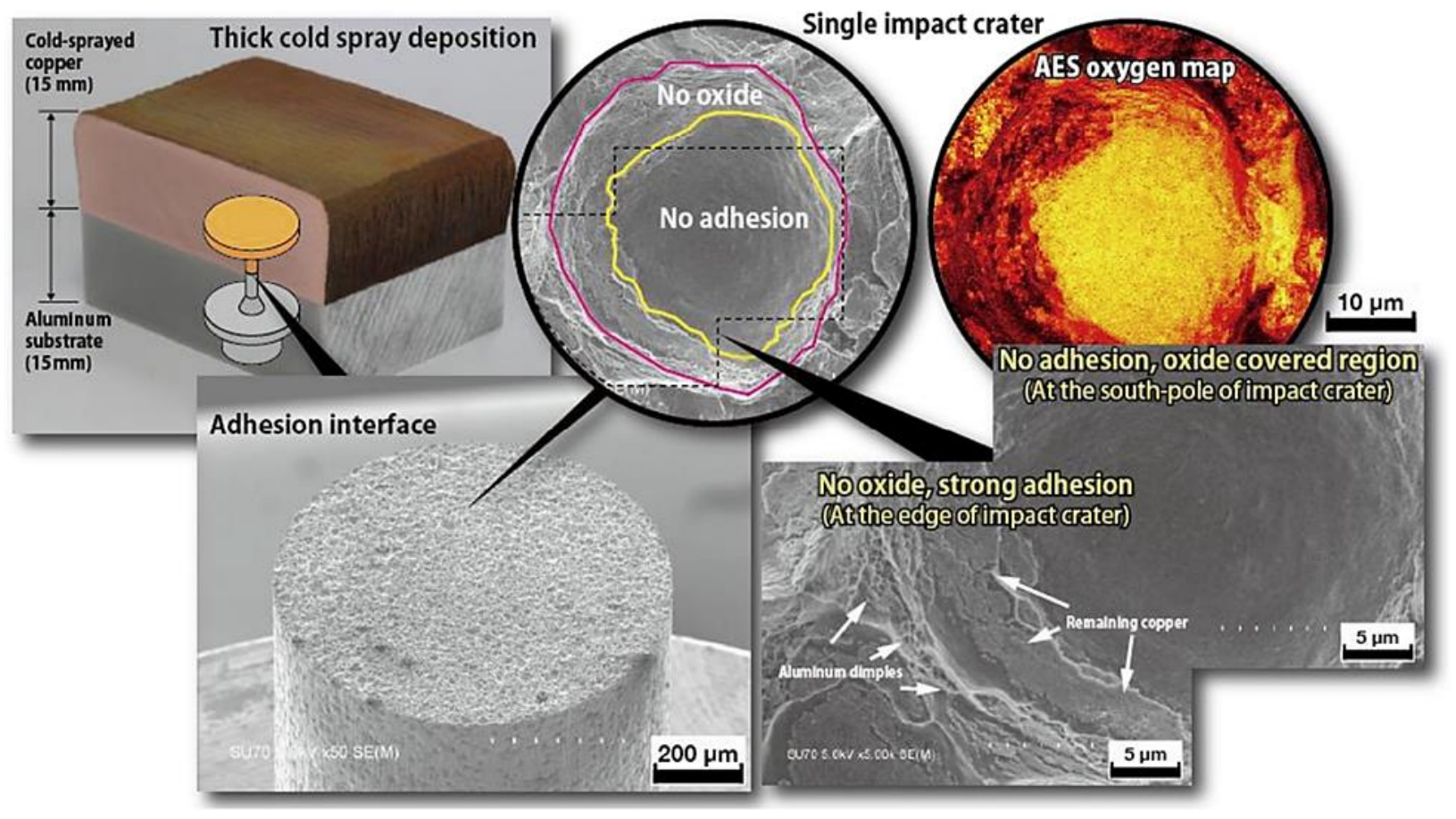

Figure 15. A pictorial view representing fractographs of cold sprayed $\mathrm{Cu}$ on $\mathrm{Al}$ exposed after adhesion testing showing bonded zones and auger electron spectroscopic (AES) maps representing oxide layer zone. \{Reprinted by permission from, Springer Nature, Journal of Thermal Spray Technology [35]\}.

\section{Effect of Nozzle Design}

Adhesion at the interface is associated with the particle impact velocity. Higher particle velocity is expected to result in better adhesion strength. The velocity of the particles at the exit of the nozzle is associated with their acceleration inside the nozzle, which is dictated by the nozzle design [132]. Moreover, particle velocity after exiting the nozzle is also influenced by nozzle design due to the bow shock effect. Therefore, the design of the CS nozzle is critical to attaining a high velocity of particles at the nozzle exit and high energy impacts at the substrate by minimizing the bow shock [67]. A cross-sectional view of a de-Laval nozzle is presented in Figure 16. 


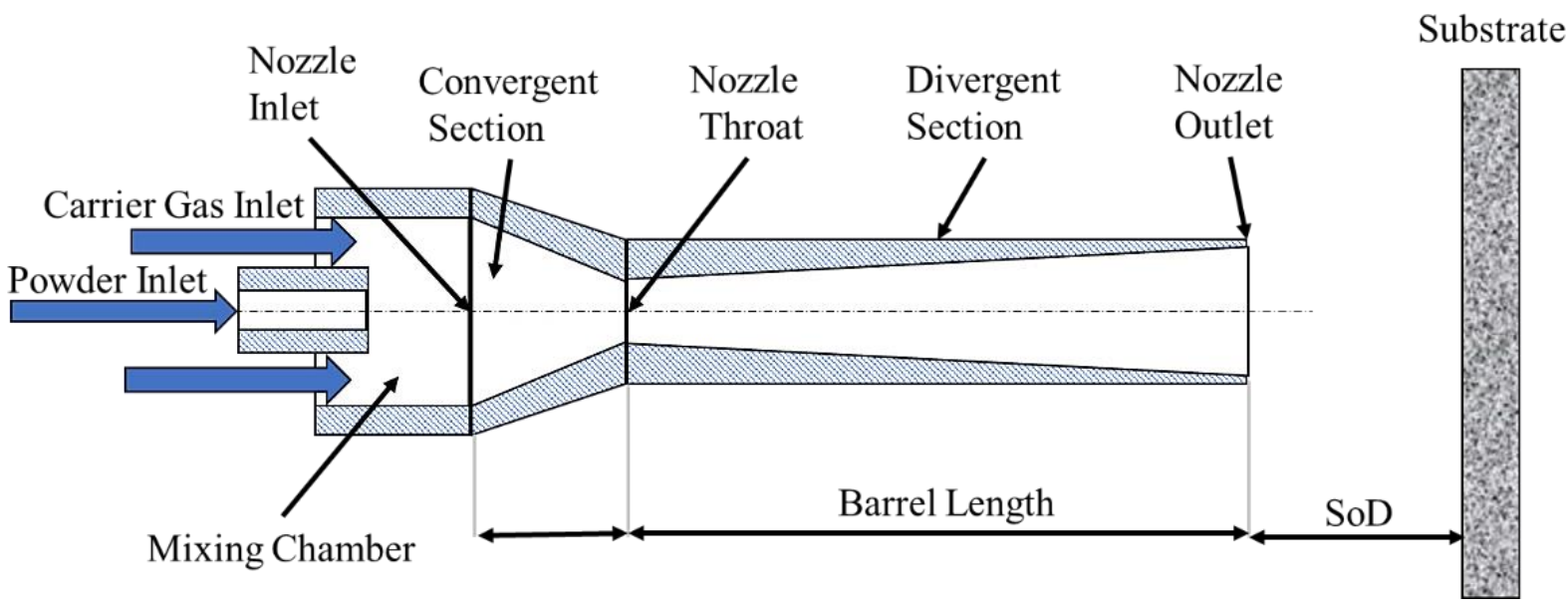

Figure 16. A cross-sectional view of a de-Laval nozzle showing its all-important parts. \{Redrawn by permission from, Elsevier, Surface and Coatings Technology, [133]\}.

An increase in barrel length of the nozzle increases the velocity of particles. Goyal et al. [134] found that the velocity of $\mathrm{Cu}$ particles of an average diameter of $12 \mu \mathrm{m}$ increased from 553 $\mathrm{m} / \mathrm{s}$ to $742 \mathrm{~m} / \mathrm{s}$, a $33 \%$ increase in particle velocity, with an increase in the barrel length from $83 \mathrm{~mm}$ to $211 \mathrm{~mm}$. Shikalov et al. [83] observed that an increase in the outlet diameter of the nozzle from $2 \mathrm{~mm}$ to $5 \mathrm{~mm}$ increased the particle velocity from $400 \mathrm{~m} / \mathrm{s}$ to $610 \mathrm{~m} / \mathrm{s}$. However, a further increase in diameter reduced the particle velocity due to divergence from the optimal expansion ratio (i.e., ratio of nozzle outlet area to throat area) of the nozzle.

Lupoi and $\mathrm{O}^{\prime} \mathrm{Neill}$ [133] noticed that the optimum expansion ratio increased with an increase in gas pressure and length of divergent section. However, it decreased with an increase in particle size, gas temperature and throat size of the nozzle. Considering all other parameters constant, the optimum expansion ratio for nitrogen as a process gas is higher than for helium gas. Furthermore, Tabbara [135] indicated that nozzles with circular cross-sections resulted in higher particle velocities at the exit compared to elliptical and square cross-sections.

\section{Proposed Methods to Understand Adhesion Mechanisms}

CS is a solid-state surface deposition process in which bulk material properties can be retained in the final deposits. Although the CS bonding mechanism is not completely understood, there are some methods that can be incorporated in CS to further understand the bonding mechanism of the CS process.

\subsection{Machine Learning}

There are many combinations of CS-related parameters that influence the adhesion strength at the interface. The successful combinations are most efficiently resolved by employing processing techniques based on machine learning that can predict the outcome. A data set can be developed from the literature and used to train the machine learning model. Several studies have been performed that can be incorporated into machine learning to optimize CS parameters, predict particle velocities and deposition efficiency $[136,137]$. The available studies are based on limited data sets and the reported data have high statistical scatter. However, the errors/scatter can be reduced by increasing the data points used to train the machine learning model. Therefore, further investigation is required for accurate predictions and an optimal set of inputs parameters for each material combination.

\subsection{Molecular Dynamic Simulations}

Bonding in CS occurs at the atomic scale and Finite Element Modelling methods are not capable of analyzing interfaces at an atomic level. Therefore, simulations based on 
molecular dynamics (MD) can be considered to analyze the bonding at the interface. MD simulations have reported the effect of impact velocity on interfacial behavior of $\mathrm{Ti}$ and $\mathrm{Ni}$ particles on Ti substrates, that have been experimentally validated [130,138-140].

MD simulation could be used to generate a data set of CS input parameters with respect to their corresponding outputs. The data sets generated from MD simulation can be validated with random experiments. Furthermore, the data sets generated from MD simulations can train the machine learning algorithms in conjunction with the data sets available in the literature. By considering the data sets from MD and actual experimentations from the literature, an optimum combination of input parameters of CS can be predicted with minimal error. These predictions can reduce the need to carry out vast experimentation.

\subsection{Online Troubleshooting}

The CS systems available in 2021 have limitations in altering the parameters during the spray process. Parameters such as gas pressure, gas temperature and powder flow rate are pre-decided and fixed before spraying. An advanced spray system addressing this limitation would facilitate the selection of optimum spray parameters. Furthermore, high-speed cameras may be integrated with the system to check the particle trajectories, striking behavior, the speed at the nozzle outlet, and impact velocity of particles during the spray process. Based on these in situ studies, the spray parameters can be monitored to achieve an optimum outcome regarding particle impact behavior, adhesion strength and desirable coating properties. Hence, online troubleshooting of the spray conditions can be performed in an integrated fashion rather than in a piece meal manner.

\subsection{Advanced Characterization Techniques}

The adhesion mechanism at particle-substrate and particle-particle interfaces has not been fully investigated at the atomic scale. Moreover, the use of advanced characterization to explore interfacial phenomena at the atomic scale in CS is limited [141]. Therefore, techniques such as atomic probe tomography (APT) and transmission electron microscopy (TEM) may be implemented to expose the mechanism behind bonding. Such techniques can probe the material at an atomic level, with which interfacial atomic behavior for a different set of material combinations can be investigated. Investigations at the atomic scale will instigate selection of effective substrate surface pre-treatments to activate atoms for metallurgical bonding, which will enhance adhesion strength.

\subsection{Spray Diagrams}

Spray diagrams highlight the influence of more than one input parameter on the interfacial and coating properties. The diagrams provide a window for a successful set of parameters. For instance, Kamaraj and Radhakrishnan [142] developed CS coating diagrams considering particle velocity $\left(V_{p}\right)$ and temperature $\left(T_{p}\right)$ as coordinates. Contours of the ratios $V_{p} / V_{c r}=0.5,0.8,1.0,1.5,2.0$, and 2.5 have been drawn to predict the deposition efficiency, cohesive strength and flattening ratio of the particles by relating these properties with the velocity ratio (Figure 17). The development of such CS diagrams for different material combinations/interfaces may enable the CS community to identify a suitable combination of $V_{p}$ and $T_{p}$ to predict bonding strength. 


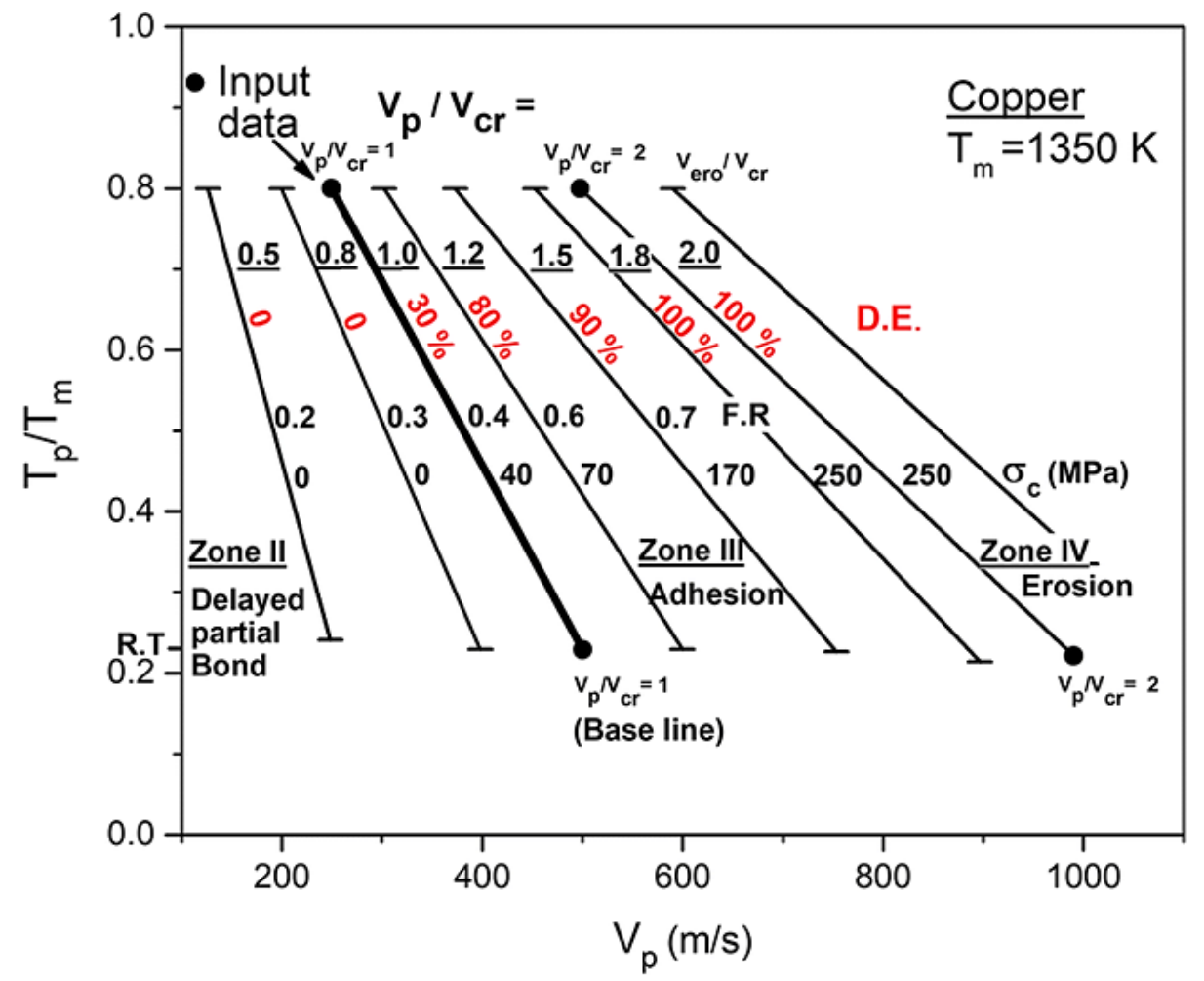

Figure 17. Cold spray coating diagram for copper with $V_{p} / V_{c r}$ contours and DE, $\sigma_{\mathrm{c}}$ and FR. $V_{p}=$ particle velocity, $V_{c r}=$ critical velocity, $\sigma_{\mathrm{c}}=$ cohesive strength, $\mathrm{DE}=$ deposition efficiency. \{Reprinted by permission from, Springer Nature, Journal of Thermal Spray Technology [142]\}.

\section{Concluding Remarks}

The adhesion strength in CS coating systems is mainly attributed to mechanical interlocking and metallurgical bonding. Simulation studies have shown that jet formation of the sprayed particles leads to a high adhesion strength. However, there is limited experimental evidence to verify these studies.

The primary and most important aspect to understand in CS is the adhesion mechanism. The literature indicates that CS adhesion is manifested in different steps, which encompass (i) impact of particles onto the substrate, (ii) breakage of any oxide layer, (iii) impingement of particle(s) into the substrate, (iv) adiabatic shear instability and/or severe plastic deformation at the interfacial area triggering localized melting at the interface, $(\mathrm{v})$ viscous flow of the interfacial material, (vi) flushing of the broken oxide layer instigating direct contact of the particle-substrate surfaces, (vii) formation of metallurgical bonds at the direct contacts, (viii) jet formation, and (ix) mechanical interlocking of the jetted material due to impact of forthcoming striking particles

There are other phenomena that influence adhesion mechanisms. For instance, recrystallization and generation of compressive residual stresses at the vicinity of the interface facilitates metallurgical bonding. However, the bow-shock effect diminishes bonding by reducing the particle impact velocity. There are several factors associated with spray conditions, feedstock properties and substrate state that influence the adhesion mechanism. The critical nature of each factor with respect to its influence on the bonding mechanism has not been assessed and needs further investigation. For example, the influence of gas pressure on adhesion strength is greater than the torch traverse speed, whereas the feedstock material has a greater influence on adhesion strength than oxidation of the feedstock. In addition, the substrate material has a more significant influence of the adhesion mechanism than the substrate temperature.

Further understanding of each CS parameter can expose the science of adhesion mechanisms. Additionally, the integration of machine learning, advanced characterization 
techniques, spray diagrams, online control of the spray process, and molecular dynamic simulations can assist in deciphering adhesion mechanisms at the interface of CS coatings.

Author Contributions: Conceptualization, S.S. and H.S.; methodology, S.S. and H.S.; formal analysis, S.S., H.S. and C.C.B.; investigation, S.S. and H.S.; resources, H.S. and C.C.B.; writing-original draft preparation, S.S.; writing-review and editing, S.S., H.S., C.C.B. and R.K.S.R.; supervision H.S. and C.C.B.; funding acquisition, H.S. and C.C.B. All authors have read and agreed to the published version of the manuscript.

Funding: Harpreet Singh and Surinder Singh acknowledge the financial support from the Department of Science and Technology-Funds for Improvement in Science and Technology (DST-FIST) INDIA, Grant number: SR/FST/ETI-379/2014 in creating facilities to carry out some of the reported work. This work was also supported by the Department of Atomic Energy (DAE), Board of Research in Nuclear Sciences (BRNS), INDIA through the project entitled "Development of thick pure $\mathrm{Cu}$ cladding/coating on SS304/SS316 substrates with cold-spray technology" bearing sanction number 39/19/2015-BRNS, which is gratefully acknowledged by Harpreet Singh and Surinder Singh. Christopher C. Berndt and Surinder Singh acknowledge the support from Australian Research Council (ARC) Industrial Transformation Training Centre (ITTC) for Surface Engineering for Advanced Materials (SEAM) scheme via award IC180100005.

Institutional Review Board Statement: Not applicable.

Informed Consent Statement: Not applicable.

Data Availability Statement: All data is available from the provided reference list of this review.

Conflicts of Interest: There is no conflict of interest to declare.

\section{References}

1. Ang, A.S.M.; Berndt, C.C.; Sesso, M.L.; Anupam, A.; Praveen, S.; Kottada, R.S.; Murty, B.S. Plasma-sprayed high entropy alloys: Microstructure and properties of AlCoCrFeNi and MnCoCrFeNi. Metall. Mater. Trans. 2015, 46, 791-800. [CrossRef]

2. Lima, R.S.; Kucuk, A.; Berndt, C.C.; Karthikeyan, J.; Kay, C.M.; Lindemann, J. Deposition efficiency, mechanical properties and coating roughness in cold-sprayed titanium. J. Mater. Sci. Lett. 2002, 21, 1687-1689. [CrossRef]

3. Niu, X.; Singh, S.; Garg, A.; Singh, H.; Panda, B.; Peng, X.; Zhang, Q. Review of materials used in laser-aided additive manufacturing processes to produce metallic products. Front. Mech. Eng. 2019, 14, 282-298. [CrossRef]

4. Espallargas, N. Future development of thermal spray coatings: Types, Designs, Manufacture and Applications. In Woodhead Publishing Series in Metals and Surface Engineering: Number 65; Elsevier, Woodhead Publishing: Cambridge, UK, 2015; pp. 27-28. ISBN 978-0-85709-774-3. [CrossRef]

5. Abadias, G.; Chason, E.; Keckes, J.; Sebastiani, M.; Thompson, G.B.; Barthel, E.; Doll, G.L.; Murray, C.E.; Stoessel, C.H.; Martinu, L. Review article: Stress in thin films and coatings: Current status, challenges, and prospects. J. Vac. Sci. Technol. A Vac. Surf. Film. 2018, 36, 020801. [CrossRef]

6. Meghwal, A.; Anupam, A.; Murty, B.S.; Berndt, C.C.; Kottada, R.S.; Ang, A.S.M. Thermal spray high-entropy alloy coatings: A review. J. Therm. Spray Technol. 2020, 29, 857-893. [CrossRef]

7. Singh, S.; Singh, P.; Singh, H.; Buddu, R.K. Characterization and comparison of copper coatings developed by low pressure cold spraying and laser cladding techniques. Mater. Today Proc. 2019, 18, 830-840. [CrossRef]

8. Frey, H.; Khan, H.R. Handbook of Thin-Film Technology; Springer: Berlin/Heidelberg, Germany, 2015; ISBN 978-3-642-05429-7. [CrossRef]

9. Singh, S.; Kumar, M.; Sodhi, G.P.S.; Buddu, R.K.; Singh, H. Development of thick copper claddings on SS316L steel for in-vessel components of fusion reactors and copper-cast iron canisters. Fusion Eng. Des. 2018, 128, 126-137. [CrossRef]

10. Papyrin, A.; Kosarev, V.; Klinkov, S.; Alkhimov, A.; Fomin, V.M. Cold Spray Technology; Elsevier Science: Amsterdam, The Netherlands, 2006; ISBN 978-0-08-046548-7. Available online: https://books.google.com.au/books?id=XjZMWNVvgLAC (accessed on 12 December 2021).

11. Segall, A.E.; Papyrin, A.N.; Conway, J.C.; Shapiro, D. A cold-gas spray coating process for enhancing titanium. J. Miner. Met. Mater. Soc. 1998, 50, 52-54. [CrossRef]

12. Assadi, H.; Kreye, H.; Gärtner, F.; Klassen, T. Cold spraying-A materials perspective. Acta Mater. 2016, 116, 382-407. [CrossRef]

13. Assadi, H.; Gärtner, F.; Stoltenhoff, T.; Kreye, H. Bonding mechanism in cold gas spraying. Acta Mater. 2003, 51, 4379-4394. [CrossRef]

14. Hussain, T.; McCartney, D.G.; Shipway, P.H.; Zhang, D. Bonding mechanisms in cold spraying: The contributions of metallurgical and mechanical components. J. Therm. Spray Technol. 2009, 18, 364-379. [CrossRef]

15. Grujicic, M.; Zhao, C.; DeRosset, W.; Helfritch, D. Adiabatic shear instability based mechanism for particles/substrate bonding in the cold-gas dynamic-spray process. Mater. Eng. 2004, 25, 681-688. [CrossRef] 
16. Hussain, T. Cold spraying of titanium: A review of bonding mechanisms, microstructure and properties. KEM 2012, 533, 53-90. [CrossRef]

17. Schmidt, T.; Assadi, H.; Gärtner, F.; Richter, H.; Stoltenhoff, T.; Kreye, H.; Klassen, T. From particle acceleration to impact and bonding in cold spraying. J. Therm. Spray Technol. 2009, 18, 794-808. [CrossRef]

18. Hassani-Gangaraj, M.; Veysset, D.; Nelson, K.A.; Schuh, C.A. Impact-bonding with aluminum, silver, and gold microparticles: Toward understanding the role of native oxide layer. Appl. Surf. Sci. 2019, 476, 528-532. [CrossRef]

19. Drehmann, R.; Grund, T.; Lampke, T.; Wielage, B.; Manygoats, K.; Schucknecht, T.; Rafaja, D. Splat formation and adhesion mechanisms of cold gas-sprayed $\mathrm{Al}$ coatings on $\mathrm{Al}_{2} \mathrm{O}_{3}$ substrates. J. Therm. Spray Technol. 2014, 23, 68-75. [CrossRef]

20. Borchers, C.; Stoltenhoff, T.; Gäartner, F.; Kreye, H.; Assadi, H. Deformation microstructure of cold gas sprayed coatings. MRS Proc. 2001, 673, P7.10.1-P7.10.6. [CrossRef]

21. Gilmore, D.L.; Dykhuizen, R.C.; Neiser, R.A.; Roemer, T.J.; Smith, M.F. Particle velocity and deposition efficiency in the cold spray process. J. Therm. Spray Technol. 1999, 8, 576-582. [CrossRef]

22. Raletz, F.; Vardelle, M.; Ezo'o, G. Critical particle velocity under cold spray conditions. Surf. Coat. Technol. 2006, 201, 1942-1947. [CrossRef]

23. Guetta, S.; Berger, M.H.; Borit, F.; Guipont, V.; Jeandin, M.; Boustie, M.; Ichikawa, Y.; Sakaguchi, K.; Ogawa, K. Influence of particle velocity on adhesion of cold-sprayed splats. J. Therm. Spray Technol. 2009, 18, 331-342. [CrossRef]

24. Wang, F.F.; Li, W.Y.; Yu, M.; Liao, H.L. Prediction of critical velocity during cold spraying based on a coupled thermomechanical eulerian model. J. Therm. Spray Technol. 2014, 23, 60-67. [CrossRef]

25. Yu, M.; Li, W.-Y.; Wang, F.F.; Suo, X.K.; Liao, H.L. Effect of particle and substrate preheating on particle deformation behavior in cold spraying. Surf. Coat. Technol. 2013, 220, 174-178. [CrossRef]

26. Ganesan, A.; Affi, J.; Yamada, M.; Fukumoto, M. Bonding behavior studies of cold sprayed copper coating on the PVC polymer substrate. Surf. Coat. Technol. 2012, 207, 262-269. [CrossRef]

27. Razavipour, M.; Rahmati, S.; Zúñiga, A.; Criado, D.; Jodoin, B. Bonding mechanisms in cold spray: Influence of surface oxidation during powder storage. J. Therm. Spray Technol. 2021, 30, 304-323. [CrossRef]

28. Nikbakht, R.; Seyedein, S.H.; Kheirandish, S.; Assadi, H.; Jodoin, B. Asymmetrical bonding in cold spraying of dissimilar materials. Appl. Surf. Sci. 2018, 444, 621-632. [CrossRef]

29. Neshastehriz, M.; Smid, I.; Segall, A.E.; Eden, T.J. On the bonding mechanism in cold spray of deformable Hex-BN-Ni clusters. J. Therm. Spray Technol. 2016, 25, 982-991. [CrossRef]

30. Loke, K.; Zhang, Z.Q.; Narayanaswamy, S.; Koh, P.K.; Luzin, P.; Herold, T.G.; Ang, A.S.M. Residual stress analysis of cold spray coatings sprayed at angles using through-thickness neutron diffraction measurement. J. Therm. Spray Technol. 2021, 30, 1810-1826. [CrossRef]

31. Xie, Y.; Chen, C.; Planche, M.-P.; Deng, S.; Huang, R.; Ren, Z.; Liao, H. Strengthened peening effect on metallurgical bonding formation in cold spray additive manufacturing. J. Therm. Spray Technol. 2019, 28, 769-779. [CrossRef]

32. Schmidt, T.; Gärtner, F.; Assadi, H.; Kreye, H. Development of a generalized parameter window for cold spray deposition. Acta Mater. 2006, 54, 729-742. [CrossRef]

33. Kromer, R.; Danlos, Y.; Costil, S. Cold gas-sprayed deposition of metallic coatings onto ceramic substrates using laser surface texturing pre-treatment. J. Therm. Spray Technol. 2018, 27, 809-817. [CrossRef]

34. Ichikawa, Y.; Tokoro, R.; Ogawa, K. Investigation of cold spray bonding mechanism focusing on the thin oxide film present in the deposition interface. In Proceedings of the International Thermal Spray Conference, Orlando, FL, USA, 7-10 May 2018; pp. 238-241, ISBN 9781627081603.

35. Ichikawa, Y.; Tokoro, R.; Tanno, M.; Ogawa, K. Elucidation of cold-spray deposition mechanism by auger electron spectroscopic evaluation of bonding interface oxide film. Acta Mater. 2019, 164, 39-49. [CrossRef]

36. Chang, Y.; Mohanty, P.; Karmarkar, N.; Khan, M.T.; Wang, Y.; Wang, J. Microstructure and properties of Cu-Cr coatings deposited by cold spraying. Vacuum 2020, 171, 109032. [CrossRef]

37. Fukumoto, M.; Tanabe, K.; Yamada, M.; Yamaguchi, E. Clarification of deposition mechanism of copper particle in cold spray process. J. Jpn. Weld. Soc. 2007, 25, 537-541. [CrossRef]

38. Barradas, S.; Molins, R.; Jeandin, M.; Arrigoni, M.; Boustie, M.; Bolis, C.; Berthe, L.; Ducos, M. Application of laser shock adhesion testing to the study of the interlamellar strength and coating-substrate adhesion in cold-sprayed copper coating of aluminum. Surf. Coat. Technol. 2005, 197, 18-27. [CrossRef]

39. Fukumoto, M.; Mashiko, M.; Yamada, M.; Yamaguchi, E. Deposition behavior of copper fine particles onto flat substrate surface in cold spraying. J. Therm. Spray Technol. 2010, 19, 89-94. [CrossRef]

40. Flanagan, J.; Schütze, P.; Dunne, C.; Twomey, B.; Stanton, K.T. Use of a blast coating process to promote adhesion between aluminium surfaces for the automotive industry. J. Adhes. 2020, 96, 580-601. [CrossRef]

41. Wüstefeld, C.; Rafaja, D.; Motylenko, M.; Ullrich, C.; Drehmann, R.; Grund, T.; Lampke, T.; Wielage, B. Local heteroepitaxy as an adhesion mechanism in aluminium coatings cold gas sprayed on AlN substrates. Acta Mater. 2017, 128, 418-427. [CrossRef]

42. Ang, A.S.M.; Berndt, C.C.; Cheang, P. Deposition effects of WC particle size on cold sprayed WC-Co coatings. Surf. Coat. Technol. 2011, 205, 3260-3267. [CrossRef]

43. Lima, R.S.; Karthikeyan, J.; Kay, C.M.; Lindemann, J.; Berndt, C.C. Microstructural characteristics of cold-sprayed nanostructured WC-Co coatings. Thin Solid Film. 2002, 416, 129-135. [CrossRef] 
44. Nunthavarawong, P.; Sacks, N.; Botef, I. Effect of powder feed rate on the mechanical properties of WC-5 wt $\%$ Ni coatings deposited using low pressure cold spray. Int. J. Refract. Met. Hard Mater. 2016, 61, 230-237. [CrossRef]

45. Christoulis, D.K.; Guetta, S.; Guipont, V.; Jeandin, M. The influence of the substrate on the deposition of cold-sprayed titanium: An experimental and numerical study. J. Therm. Spray Technol. 2011, 20, 523-533. [CrossRef]

46. Jami, H.; Jabbarzadeh, A. Effect of particle shape on mechanics of impact in the deposition of titanium nanoparticles on a titanium substrate. Surf. Coat. Technol. 2020, 394, 125880. [CrossRef]

47. Irinah Omar, N.; Selvami, S.; Kaisho, M.; Yamada, M.; Yasui, T.; Fukumoto, M. Deposition of titanium dioxide coating by the cold-spray process on annealed stainless steel substrate. Coatings 2020, 10, 991. [CrossRef]

48. Cao, C.; Li, W.; Yang, K.; Li, C.; Ji, G. Influence of substrate hardness and thermal characteristics on microstructure and mechanical properties of cold sprayed TC4 titanium alloy coatings. Cailiao Daobao/Mater. Rev. 2019, 33, 277-282. [CrossRef]

49. Dietrich, D.; Wielage, B.; Lampke, T.; Grund, T.; Kümme, S. Evolution of microstructure of cold-spray aluminum coatings on $\mathrm{Al}_{2} \mathrm{O}_{3}$ substrates. Adv. Eng. Mater. 2011, 14, 275-278. [CrossRef]

50. Ko, K.H.; Choi, J.O.; Lee, H. The interfacial restructuring to amorphous: A new adhesion mechanism of cold-sprayed coatings. Mater. Lett. 2016, 175, 13-15. [CrossRef]

51. Ziemian, C.W.; Wright, W.J.; Cipoletti, D.E. Influence of impact conditions on feedstock deposition behavior of cold-sprayed Fe-based metallic glass. J. Therm. Spray Technol. 2018, 27, 843-856. [CrossRef]

52. Vidaller, M.V.; List, A.; Gaertner, F.; Klassen, T.; Dosta, S.; Guilemany, J.M. Single impact bonding of cold sprayed Ti-6Al-4V powders on different substrates. J. Therm. Spray Technol. 2015, 24, 644-658. [CrossRef]

53. Welk, B.A.; Williams, R.E.A.; Viswanathan, G.B.; Gibson, M.A.; Liaw, P.K.; Fraser, H.L. Nature of the interfaces between the constituent phases in the high entropy alloy CoCrCuFeNiAl. Ultramicroscopy 2013, 134, 193-199. [CrossRef]

54. Kumar, S.; Bae, G.; Lee, C. Influence of substrate roughness on bonding mechanism in cold spray. Surf. Coat. Technol. 2016, 304, 592-605. [CrossRef]

55. Singh, S.; Singh, H.; Chaudhary, S.; Buddu, R.K. Effect of substrate surface roughness on properties of cold-sprayed copper coatings on SS316L steel. Surf. Coat. Technol. 2020, 389, 125619. [CrossRef]

56. Lock Sulen, W.; Ravi, K.; Bernard, C.; Ichikawa, Y.; Ogawa, K. Deposition mechanism analysis of cold-sprayed fluoropolymer coatings and its wettability evaluation. J. Therm. Spray Technol. 2020, 29, 1643-1659. [CrossRef]

57. Hassani-Gangaraj, M.; Veysset, D.; Champagne, V.K.; Nelson, K.A.; Schuh, C.A. Adiabatic shear instability is not necessary for adhesion in cold spray. Acta Mater. 2018, 158, 430-439. [CrossRef]

58. Assadi, H.; Gärtner, F.; Klassen, T.; Kreye, H. Comment on "Adiabatic shear instability is not necessary for adhesion in cold spray". Scr. Mater. 2019, 162, 512-514. [CrossRef]

59. Hassani-Gangaraj, M.; Veysset, D.; Champagne, V.K.; Nelson, K.A.; Schuh, C.A. Response to comment on "Adiabatic shear instability is not necessary for adhesion in cold spray". Scr. Mater. 2019, 162, 515-519. [CrossRef]

60. Kim, G.H.; Park, C.K.; Ahn, H.J.; Kim, H.S.; Hong, K.H.; Jin, S.W.; Lee, H.G.; Fukanuma, H.; Huang, R.; Roh, B.R.; et al. Fabrication feasibility study on copper cold spray in tokamak system. Fusion Eng. Des. 2015, 98-99, 1576-1579. [CrossRef]

61. Ioki, K.; Barabash, V.; Bachmann, C.; Chappuis, P.; Choi, C.H.; Cordier, J.-J.; Giraud, B.; Gribov, Y.; Heitzenroeder, P.; Her, N.; et al. Design finalization and material qualification towards procurement of the ITER vacuum vessel. J. Nucl. Mater. 2011, 417, 860-865. [CrossRef]

62. Singh, S.; Chaudhary, S.; Singh, H. Effect of electroplated interlayers on properties of cold-sprayed copper coatings on SS316L steel. Surf. Coat. Technol. 2019, 375, 54-65. [CrossRef]

63. Singh, S.; Singh, H.; Buddu, R.K. Microstructural investigations on bonding mechanisms of cold-sprayed copper with SS316L steel. Surf. Eng. 2020, 36, 1067-1080. [CrossRef]

64. Arabgol, Z.; Vidaller, M.V.; Assadi, H.; Gärtner, F.; Klassen, T. Influence of thermal properties and temperature of substrate on the quality of cold-sprayed deposits. Acta Mater. 2017, 127, 287-301. [CrossRef]

65. Sun, W.; Tan, A.W.Y.; Bhowmik, A.; Marinescu, I.; Song, X.; Zhai, W.; Li, F.; Liu, E. Deposition characteristics of cold sprayed inconel 718 particles on inconel 718 substrates with different surface conditions. Mater. Sci. Eng. 2018, 720, 75-84. [CrossRef]

66. Ichikawa, Y.; Ogawa, K. Effect of substrate surface oxide film thickness on deposition behavior and deposition efficiency in the cold spray process. J. Therm. Spray Technol. 2015, 24, 1269-1276. [CrossRef]

67. Jodoin, B. Cold spray nozzle mach number limitation. J. Therm. Spray Technol. 2002, 11, 496-507. [CrossRef]

68. Dowding, I.; Hassani, M.; Sun, Y.; Veysset, D.; Nelson, K.A.; Schuh, C.A. Particle size effects in metallic microparticle impactbonding. Acta Mater. 2020, 194, 40-48. [CrossRef]

69. Chun, D.-M.; Choi, J.-O.; Lee, C.S.; Ahn, S.-H. Effect of stand-off distance for cold gas spraying of fine ceramic particles $(<5 \mu \mathrm{m})$ under low vacuum and room temperature using nano-particle deposition system (NPDS). Surf. Coat. Technol. 2012, 206, $2125-2132$. [CrossRef]

70. Wang, Z.; Cai, S.; Jin, K.; Wang, X.; Chen, W. In-flight aggregation and deposition behaviour of particles in low pressure cold spray. Surf. Coat. Technol. 2021, 409, 126875. [CrossRef]

71. Rokni, M.R.; Nutt, S.R.; Widener, C.A.; Champagne, V.K.; Hrabe, R.H. Review of relationship between particle deformation, coating microstructure, and properties in high-pressure cold spray. J. Therm. Spray Technol. 2017, 26, 1308-1355. [CrossRef]

72. Wang, Q.; Birbilis, N.; Zhang, M.-X. On the formation of a diffusion bond from cold-spray coatings. Metall. Mater. Trans. 2012, 43, 1395-1399. [CrossRef] 
73. Huang, J.; Ma, W.; Xie, Y.; Fukanum, H.; Zhang, K.; Wang, G.; Huang, R. Influence of cold gas spray processing conditions on the properties of 316L stainless steel coatings. Surf. Eng. 2019, 35, 784-791. [CrossRef]

74. Papyrin, A. Cold spray technology. Adv. Mater. Process. 2001, 159, 49-51. Available online: https://www.researchgate.net/ publication/279896053_Cold_spray_technology (accessed on 13 December 2021).

75. Cavaliere, P. Cold-Spray Coatings: Recent Trends and Future Perspectives; Springer International Publishing: Cham, Switzerland, 2017; ISBN 978-3-319-67183-3.

76. Maev, R.G.; Leshchynsky, V. Impact features of gas dynamic spray technology. In Introduction to Low Pressure Gas Dynamic Spray; John Wiley \& Sons Ltd.: Hoboken, NJ, USA, 2007; pp. 11-35. ISBN 978-3-527-62190-3.

77. Maev, R.G.; Leshchynsky, V. Low-pressure GDS system. In Introduction to Low Pressure Gas Dynamic Spray; John Wiley \& Sons Ltd.: Hoboken, NJ, USA, 2007; pp. 65-78. ISBN 978-3-527-62190-3.

78. Maev, R.G.; Leshchynsky, V. General analysis of low-pressure GDS. In Introduction to Low Pressure Gas Dynamic Spray; John Wiley \& Sons Ltd.: Hoboken, NJ, USA, 2007; pp. 79-94. ISBN 978-3-527-62190-3. [CrossRef]

79. Smith, M.F. Introduction to Cold Spray; Chapter 1; Pub. ASM International: Cleveland, OH, USA, 2016 ; pp. 2-11.

80. Ning, X.-J.; Jang, J.-H.; Kim, H.-J. The effects of powder properties on in-flight particle velocity and deposition process during low pressure cold spray process. Appl. Surf. Sci. 2007, 253, 7449-7455. [CrossRef]

81. Winnicki, M.; Piwowarczyk, T.; Małachowska, A.; Ambroziak, A. Effect of gas pressure and temperature on stereometric properties of $\mathrm{Al}+\mathrm{Al}_{2} \mathrm{O}_{3}$ composite coatings deposited by LPCS method. Arch. Metall. Mater. 2014, 59, 879-886. [CrossRef]

82. Zhang, H.; Zhang, J.; Shan, A.; Wu, J.; Song, H. Effects of gas temperature on bonding and deformation behavior of cold-sprayed Ni particles. Jinshu Xuebao/Acta Metall. Sin. 2007, 43, 823-828.

83. Shikalov, V.S.; Klinkov, S.V.; Kosarev, V.F. Effect of gas temperature and nozzle traverse speed on the deposition efficiency in cold spraying. Thermophys. Aeromech. 2021, 28, 77-86. [CrossRef]

84. Meng, X.; Zhang, J.; Zhao, J.; Liang, Y.; Zhang, Y. Influence of gas temperature on microstructure and properties of cold spray 304SS coating. J. Mater. Sci. Technol. 2011, 27, 809-815. [CrossRef]

85. Adachi, S.; Ueda, N. Effect of cold-spray conditions using a nitrogen propellant gas on AISI 316L stainless steel-coating microstructures. Coatings 2017, 7, 87. [CrossRef]

86. Zahiri, S.H.; Fraser, D.; Gulizia, S.; Jahedi, M. Effect of processing conditions on porosity formation in cold gas dynamic spraying of copper. J. Therm. Spray Technol. 2006, 15, 422-430. [CrossRef]

87. Cortés, R.; Garrido, M.A.; Rico, A.; Múnez, C.J.; Poza, P.; Martos, A.M.; Dosta, S.; Cano, I.G. Effect of processing conditions on the mechanical performance of stainless steel cold sprayed coatings. Surf. Coat. Technol. 2020, 394, 125874. [CrossRef]

88. Lee, H.; Shin, H.; Ko, K. Effects of gas pressure of cold spray on the formation of Al-based intermetallic compound. J. Therm. Spray Technol. 2010, 19, 102-109. [CrossRef]

89. Luo, X.-T.; Wei, Y.-K.; Wang, Y.; Li, C.-J. Microstructure and mechanical property of $\mathrm{Ti}$ and $\mathrm{Ti}_{6} \mathrm{~A}_{14} \mathrm{~V}$ prepared by an in-situ shot peening assisted cold spraying. Mater. Des. 2015, 85, 527-533. [CrossRef]

90. Bolesta, A.V.; Fomin, V.M.; Sharafutdinov, M.R.; Tolochko, B.P. Investigation of interface boundary occurring during cold gas-dynamic spraying of metallic particles. Nucl. Instrum. Methods Phys. Res. Sect. A Accel. Spectrometers Detect. Assoc. Equip. 2001, 470, 249-252. [CrossRef]

91. Tan, A.; Lek, J.; Sun, W.; Bhowmik, A.; Marinescu, I.; Song, X.; Zhai, W.; Li, F.; Dong, Z.; Boothroyd, C.; et al. Influence of particle velocity when propelled using $\mathrm{N}_{2}$ or $\mathrm{N}_{2}$-He mixed gas on the properties of cold-sprayed $\mathrm{Ti}_{6} \mathrm{~A}_{14} \mathrm{~V}$ coatings. Coatings 2018, 8, 327 . [CrossRef]

92. Rathod, W.S.; Khanna, A.S.; Karthikeyan, J.; Rathod, R.C. Effect of $\mathrm{N}_{2}$ and He carrier gases on oxidation behavior of cold sprayed CoNiCrAlY powder to deposit bond coats. Trans. Indian Inst. Met. 2014, 67, 247-262. [CrossRef]

93. Khun, N.W.; Tan, A.W.Y.; Bi, K.J.W.; Liu, E. Effects of working gas on wear and corrosion resistances of cold sprayed Ti-6Al-4V coatings. Surf. Coat. Technol. 2016, 302, 1-12. [CrossRef]

94. Cetin, O.; Tazegul, O.; Kayali, E.S. Effect of parameters to the coating formation during cold spray process. In Proceedings of the 2nd World Congress on Mechanical, Chemical, and Material Engineering (MCM'16), Budapest, Hungary,, $22-23$ August 2016. [CrossRef]

95. Góral, A.; Źórawski, W.; Makrenek, M. The Effect of the Standoff Distance on the Microstructure and Mechanical Properties of Cold Sprayed $\mathrm{Cr}_{3} \mathrm{C}_{2}-25\left(\mathrm{Ni}_{20} \mathrm{Cr}\right)$ Coatings. Surf. Coat. Technol. 2019, 361, 9-18. [CrossRef]

96. Feng, S.Q.; Ma, B.; Wang, X.L.; Liu, G.; Zheng, Z.Y.; Pan, L.P. Effects of standoff distance and particle size on quality of NiCoCrAlY coating by cold spraying. Appl. Mech. Mater. 2014, 513, 265-268. [CrossRef]

97. Seraj, R.A.; Abdollah-zadeh, A.; Dosta, S.; Canales, H.; Assadi, H.; Cano, I.G. The effect of traverse speed on deposition efficiency of cold sprayed stellite 21. Surf. Coat. Technol. 2019, 366, 24-34. [CrossRef]

98. Rezaeian, A.; Wong, W.; Yue, S.; Irissou, E.; Legoux, J.-G. Effect of gun traverse speed on microstructure and bond strength of cold sprayed Ti6Al4V and Ti coatings. In Proceedings of the Materials Science and Technology Conference, Association for Iron \& Steel Technology, Warrendale, PA, USA, 25-29 October 2009; Volume 4, pp. 2268-2278. Available online: https: //www.tib.eu/de/suchen/id/BLCP\%3ACN075294837 (accessed on 13 December 2021).

99. Tan, A.W.-Y.; Sun, W.; Phang, Y.P.; Dai, M.; Marinescu, I.; Dong, Z.; Liu, E. Effects of traverse scanning speed of spray nozzle on the microstructure and mechanical properties of cold-sprayed $\mathrm{Ti}_{6} \mathrm{~A}_{14} \mathrm{~V}$ coatings. J. Therm. Spray Technol. 2017, 26, 1484-1497. [CrossRef] 
100. Li, G.; Wang, X.; Li, W. Effect of different incidence angles on bonding performance in cold spraying. Trans. Nonferrous Met. Soc. China 2007, 17, 116-121. [CrossRef]

101. Wkh, G.; Wkh, L.; Dqg, R. Effect of spray angle on deposition characteristics in cold spraying. In Proceedings of the International Therm. Spray Conference 2003: Advancing the Science \& Applying the Technology, Orlando, FL, USA, 5-8 May 2003; Moreau, C., Marple, B., Eds.; ASM Int.: Materials Park, OH, USA, 2003; Volume 2, pp. 91-96, ISBN 10871707853. Available online: http:/ / www.artostw.com/uploads/techdoc/files/TechnicalDocs_20190424141603.pdf (accessed on 13 December 2021).

102. Karthikeyan, J. Cold spray technology: International status and USA efforts. Mater. Sci. 2004, 44203, 1-14. Available online: www.asbindustries.com/documents/int_status_report.pdf (accessed on 13 December 2021).

103. Yin, S.; Suo, X.; Su, J.; Guo, Z.; Liao, H.; Wang, X. Effects of substrate hardness and spray angle on the deposition behavior of cold-sprayed Ti particles. J. Therm. Spray Technol. 2014, 23, 76-83. [CrossRef]

104. Feng, W. Effects of particle shape and temperature on its deposition character in cold spray. Cailiao Daobao/Mater. Rev. 2017, 31, 138-142. [CrossRef]

105. Nikbakht, R.; Assadi, H.; Jahani, K.; Saadati, M.; Jodoin, B. Cold spray deformation and deposition of blended feedstock powders not necessarily obey the rule of mixture. Surf. Coat. Technol. 2021, 424, 127644. [CrossRef]

106. Wong, W.; Vo, P.; Irissou, E.; Ryabinin, A.N.; Legoux, J.-G.; Yue, S. Effect of particle morphology and size distribution on cold-sprayed pure titanium coatings. J. Spray Tech. 2013, 22, 1140-1153. [CrossRef]

107. Wang, L.-S.; Zhou, H.-F.; Zhang, K.-J.; Wang, Y.-Y.; Li, C.-X.; Luo, X.-T.; Yang, G.-J.; Li, C.-J. Effect of the powder particle structure and substrate hardness during vacuum cold spraying of $\mathrm{Al}_{2} \mathrm{O}_{3}$. Ceram. Int. 2017, 43, 4390-4398. [CrossRef]

108. Wang, Y.; Normand, B.; Mary, N.; Yu, M.; Liao, H. Effects of ceramic particle size on microstructure and the corrosion behavior of cold sprayed $\mathrm{SiCp} / \mathrm{Al} 5056$ composite coatings. Surf. Coat. Technol. 2017, 315, 314-325. [CrossRef]

109. Elsenberg, A.; Busato, M.; Gärtner, F.; List, A.; Bruera, A.; Bolelli, G.; Lusvarghi, L.; Klassen, T. Influence of MAX-phase deformability on coating formation by cold spraying. J. Therm. Spray Technol. 2021, 30, 617-642. [CrossRef]

110. Go, T.; Sohn, Y.J.; Mauer, G.; Vaßen, R.; Gonzalez-Julian, J. Cold spray deposition of $\mathrm{Cr}_{2} \mathrm{AlC}$ MAX phase for coatings and bond-coat layers. J. Eur. Ceram. Soc. 2019, 39, 860-867. [CrossRef]

111. Fukumoto, M.; Wada, H.; Tanabe, K.; Yamada, M.; Yamaguchi, E.; Niwa, A.; Sugimoto, M.; Izawa, M. Effect of substrate temperature on deposition behavior of copper particles on substrate surfaces in the cold spray process. J. Therm. Spray Technol. 2007, 16, 643-650. [CrossRef]

112. Irinah, O.N.; Yamada, M.; Yasui, T.; Fukumoto, M. On the role of substrate temperature into bonding mechanism of cold sprayed titanium dioxide. IOP Conf. Ser. 2020, 920, 012009. Available online: https://iopscience.iop.org/article/10.1088/1757-899X/920/ $1 / 012009 /$ meta (accessed on 13 December 2021). [CrossRef]

113. Ghelichi, R.; Guagliano, M. Coating by the cold spray process: A state of the art. Fra. Int. Strut. 2013, 3, 30-44. [CrossRef]

114. Theimer, S.; Graunitz, M.; Schulze, M.; Gaertner, F.; Klassen, T. Optimization Adhesion in Cold Spraying onto Hard Substrates: A Case Study for Brass Coatings. J. Therm. Spray Technol. 2019, 28, 124-134. [CrossRef]

115. Chu, X.; Che, H.; Vo, P.; Chakrabarty, R.; Sun, B.; Song, J.; Yue, S. Understanding the Cold Spray Deposition Efficiencies of 316L/Fe Mixed Powders by Performing Splat Tests onto as-Polished Coatings. Surf. Coat. Technol. 2017, 324, 353-360. [CrossRef]

116. Drehmann, R.; Grund, T.; Lampke, T.; Wielage, B.; Wüstefeld, C.; Motylenko, M.; Rafaja, D. Essential Factors Influencing the Bonding Strength of Cold-Sprayed Aluminum Coatings on Ceramic Substrates. J. Therm. Spray Technol. 2018, $27,446-455$. [CrossRef]

117. Drehmann, R.; Grund, T.; Lampke, T.; Wielage, B.; Manygoats, K.; Schucknecht, T.; Rafaja, D. Interface Characterization and Bonding Mechanisms of Cold Gas-Sprayed Al Coatings on Ceramic Substrates. J. Therm. Spray Technol. 2015, 24, 92-99. [CrossRef]

118. Singh, S.; Singh, H. Effect of Electroplated Interlayers on Bonding Mechanism of Cold-Sprayed Copper on SS316L Steel Substrate. Vacuum 2020, 172, 109092. [CrossRef]

119. Perton, M.; Costil, S.; Wong, W.; Poirier, D.; Irissou, E.; Legoux, J.-G.; Blouin, A.; Yue, S. Effect of Pulsed Laser Ablation and Continuous Laser Heating on the Adhesion and Cohesion of Cold Sprayed Ti-6Al-4V Coatings. J. Therm. Spray Technol. 2012, 21, 1322-1333. [CrossRef]

120. Wang, Q.; Birbilis, N.; Zhang, M.-X. Interfacial Structure between Particles in an Aluminum Deposit Produced by Cold Spray. Mater. Lett. 2011, 65, 1576-1578. [CrossRef]

121. Xie, Y.; Planche, M.-P.; Raoelison, R.; Liao, H.; Suo, X.; Hervé, P. Effect of Substrate Preheating on Adhesive Strength of SS 316L Cold Spray Coatings. J. Therm. Spray Technol. 2016, 25, 123-130. [CrossRef]

122. Lee, K.; Lee, M.; Yu, J.; Kim, H.J. Effect of Powder Preheating Temperature on the Properties of Cu Based Amorphous Coatings by Cold Spray Deposition. J. Korean Inst. Met. Mater. 2009, 47, 728-733. [CrossRef]

123. Legoux, J.G.; Irissou, E.; Moreau, C. Effect of Substrate Temperature on the Formation Mechanism of Cold-Sprayed Aluminum, Zinc and Tin Coatings. J. Therm. Spray Technol. 2007, 16, 619-626. [CrossRef]

124. Watanabe, Y.; Yoshida, C.; Atsumi, K.; Yamada, M.; Fukumoto, M. Influence of Substrate Temperature on Adhesion Strength of Cold-Sprayed Coatings. J. Therm. Spray Technol. 2014, 24, 86-91. [CrossRef]

125. Yin, S.; Suo, X.; Xie, Y.; Li, W.; Lupoi, R.; Liao, H. Effect of Substrate Temperature on Interfacial Bonding for Cold Spray of Ni onto Cu. J. Mater. Sci. 2015, 50, 7448-7457. [CrossRef]

126. Yuan, L.; Luo, F.; Yao, J. Deposition Behavior at Different Substrate Temperatures by Using Supersonic Laser Deposition. J. Iron Steel Res. Int. 2013, 20, 87-93. [CrossRef] 
127. Ortiz-Fernandez, R.; Imbriglio, S.; Chromik, R.; Jodoin, B. The Role of Substrate Preheating on the Adhesion Strength of Cold-Sprayed Soft Particles on Hard Substrates. J. Therm. Spray Technol. 2021, 30, 655-667. [CrossRef]

128. Nastic, A.; Jodoin, B.; Poirier, D.; Legoux, J.G. Particle Temperature Effect in Cold Spray: A Study of Soft Particle Deposition on Hard Substrate. Surf. Coat. Technol. 2021, 406, 126735. [CrossRef]

129. Goldbaum, D.; Shockley, J.M.; Chromik, R.R.; Rezaeian, A.; Yue, S.; Legoux, J.-G.; Irissou, E. The Effect of Deposition Conditions on Adhesion Strength of Ti and $\mathrm{Ti}_{6} \mathrm{~A}_{14}$ V Cold Spray Splats. J. Therm. Spray Technol. 2012, 21, 288-303. [CrossRef]

130. Rahmati, S.; Zúñiga, A.; Jodoin, B.; Veiga, R. Deformation of Copper Particles upon Impact: A Molecular Dynamics Study of Cold Spray. Comput. Mater. Sci. 2020, 171, 109219. [CrossRef]

131. Rahmati, S.; Veiga, R.G.A.; Zúñiga, A.; Jodoin, B. A Numerical Approach to Study the Oxide Layer Effect on Adhesion in Cold Spray. J. Therm. Spray Technol. 2021, 30, 1777-1791. [CrossRef]

132. Jen, T.C.; Li, L.; Chen, Q.; Cui, W.; Zhang, X. Acceleration of Micro-and Nano-Particles in Supersonic de-Laval-Type Nozzle. Jisuan Lixue Xuebao/Chin. J. Comput. Mech. 2005, 22, 453-456. [CrossRef]

133. Lupoi, R.; O'Neill, W. Powder Stream Characteristics in Cold Spray Nozzles. Surf. Coat. Technol. 2011, 206, 1069-1076. [CrossRef]

134. Goyal, T.; Sharma, P.; Walia, R.S.; Sidhu, T.S. Effect of nozzle geometry on exit velocity, temprature and pressure for cold spray process. Int. J. Mater. Sci. Eng. 2011, 2, 65-72. Available online: https://www.researchgate.net/publication/271511548_Effect_of_ nozzle_geometry_on_exit_velocity_temperature_and_pressure_for_cold_spray_process (accessed on 13 December 2021).

135. Tabbara, H. Combustion, Supersonic Flow, Droplet Injection and Substrate Impingement Phenomena. Ph.D. Thesis, University of Southampton, Southampton, UK, 2012. Available online: https:/ / eprints.soton.ac.uk/348993/1/TABBARA\%2520THESIS.pdf (accessed on 13 December 2021).

136. Canales, H.; Cano, I.G.; Dosta, S. Window of Deposition Description and Prediction of Deposition Efficiency via Machine Learning Techniques in Cold Spraying. Surf. Coat. Technol. 2020, 401, 126143. [CrossRef]

137. Wang, Z.; Cai, S.; Chen, W.; Ali, R.A.; Jin, K. Analysis of Critical Velocity of Cold Spray Based on Machine Learning Method with Feature Selection. J. Therm. Spray Technol. 2021, 30, 1213-1225. [CrossRef]

138. Oyinbo, S.T.; Jen, T.-C. Molecular Dynamics Investigation of Temperature Effect and Surface Configurations on Multiple Impacts Plastic Deformation in a Palladium-Copper Composite Metal Membrane (CMM): A Cold Gas Dynamic Spray (CGDS) Process. Comput. Mater. Sci. 2020, 185, 109968. [CrossRef]

139. Joshi, A.; James, S. Molecular Dynamics Simulation Study of Cold Spray Process. J. Manuf. Process. 2018, 33, 136-143. [CrossRef]

140. Temitope Oyinbo, S.; Jen, T.-C. Molecular Dynamics Simulation of Dislocation Plasticity Mechanism of Nanoscale Ductile Materials in the Cold Gas Dynamic Spray Process. Coatings 2020, 10, 1079. [CrossRef]

141. Fazi, A.; Aboulfadl, H.; Iyer, A.H.S.; Sattari, M.; Stiller, K.M.; Lokhande, P.; Thuvander, M.; Andren, H.-O. Characterization of As-Deposited Cold Sprayed Cr-Coating on Optimized ZIRLO ${ }^{\mathrm{TM}}$ Claddings. J. Nucl. Mater. 2021, 549, 152892. [CrossRef]

142. Kamaraj, M.; Radhakrishnan, V.M. Cold Spray Coating Diagram: Bonding Properties and Construction Methodology. J. Therm. Spray Technol. 2019, 28, 756-768. [CrossRef] 